\title{
Das Königlich Bayerische Kreisarchiv Bamberg und sein Neubau.
}

\author{
Von \\ Joseph Sebert, k. Reichsarchivrat, \\ Vorstand des k. Kreisarchives Bamberg.
}

Im Jahre 1905 sind bekanntlich die Archivare Deutschlands zu gemeinsamer Tagung in Bamberg zusammengetreten, jener Stadt, die so häufig glanzvolle Reichsversammlungen, Hoftage und Synoden, gar viele weltliche und geistliche Machthaber gesehen hat und mit Recht gepriesen wird nals ein anmutreiches Zentrum, um welches das westliche Oberfranken seine landschaftlichen Vorzüge sammelte und deren wechselnde Erscheinungen in charakteristischer, reizvoller Schönheit gruppierte".

Als die längst schon freudig erwarteten Gäste an einem heiteren, sonnigen Herbstmorgen hinausgezogen waren gegen den Theresienhain, einen herrlichen, fast eine Stunde langen Park mit prächtigen alten Buchen und ehrwürdigen Eichen, welchem Bamberg einen wesentlichen Teil seiner besonderen Schönheit verdankt, sahen sie sich an Ende der villengeschmückten Hainstrasse einem neuerstandenen, im Stil des späteren Barock gehaltenen Monumentalbau gegenüber, dessen vornehme Architekturformen, gediegene Pracht und glückliche Gruppierung der einzelnen Gebäudeteile Alle überraschte und bei manchem, mit den Archiven der verschiedensten Deutschen Lande wohl vertrauten Berufsgenossen das Gefühl neidloser Bewunderung und freudiger Genugtuung auslöste.

Archiralische Zeitschrift. Neue Folge. XV. 
I iesen prunkwollen Neubau nun einer bis ins Detail gehenden Besprechung zu unterziehen und den Fachmann, wie sonstigen Interessenten mit allen archiv- und bautechnischen Einzelheiten bekannt zu machen in specie über die programmatischen Forderungen bezïglich Situierung, Masseneinteilung, Kotierung und äusserer Ausstattung der Gebäude. über Verteilung der Räume in Verwaltungsbau, wie im Erd- und Obergeschosese des Mitteltraktes und der beiden Seitenflügel des Beständehauses. über massive Deckenkonstruktion, feuersichere Türabschlüsse. Vorkehrungen zur tbhaltung aufsteigender Bodenfeuchtigkeit und vor allem über die innere Einrichtung des Hauptgebäudes etc. etc. ausführlich zu berichten. ist dies Aufugabe, die ich übernommen habe und der ich in Nachstehendem gerecht $\mathrm{zu}$ werden versuche.

Vielleicht erscheint es aber nicht völlig ausserhalb des Rahmens derselben liegend und möchte am Ende nicht als ganz überflüssige, ja stürende und das Interesse für das eigentliche Thema abschwächende Beigabe sich erweis'n, wenn ich vorher noch das Wesentlichste über Entstehung, allmähliche Entwickelung und planmässige Ausgestaltung des umfangreichen, vielbenützten oberfränkis(hen Provinzialarchives biete, ${ }^{1}$ ) dessen (ikunden, Akten und Kodizes nicht nur für die (ieschichte des: alten kaiserlichen Hochstiftes Bamberg, des einstigen Fürstentums Brandenburg-Bayreuth-Kulmbach, der frinkischen Reich:ritterkantone Baunach, Gebirg und steigerwald. emollich der ehemaligen auf bamhergischem und markgräflichem Territorium gelegenen Koliegiatstifte, Abteien und Klöster von höchster Bedeutung sind, sondern auch für ausgedehnte Zeitepochen eine Hauptquelle für Ërforschung der Reichsgeschichte bilden.

Ueber die frühesten Schicksale des

hochfürstlich Bambergschen drchives. welches mit dem sogenannten Plassenburger, i. e. markgräflich Brandenburg-Bayreuthschen Archiv als der weitaus grösste und wichtigste Bestandteil des heutigen Kreisarchives zu gelten hat,

1) Bezüglich diescr geschichtlichen Daten siehe Kurrespondenzblatt des Gesamtvereins der Deutschen Geschichts- und Altertumsvereine 1905, Nr. 11 und 12, Spalte t25, Absatz 2 und 3. Neuerdings ist dieser Auszug um einen besonderen Abschnitt über das Kapitulationswesen etc. erweitert worden. 
ist soviel wie nichts bekannt. Die Anfänge seiner Geschichte verlieren sich, wie die der meisten Archive geistlicher Reichsfürsten und Korporationen in den Gewölben ihrer Hauptkirchen. hier in den Hallen jenes herrlichen Domes, den Kaiser Heinrich II. vor 900 Jahren am Sitze des von ihm gegründeten Bistums hatt. erbauen lassen. Im sogenannten Sakrarium oder "Segererwurde nämlich in der frühesten Zeit, wie aus einer Urkunde Bischofs Heinrich I. von 1247 und einer weiteren von 1254 nachweisbar ist, neben dem Iomschatze und den Domheiligtümern auch das Archiv verwahrt.

Dieses älteste Bamberger Archiv wird wohl nur von ganz bescheidenem Umfange gewesen sein und vorzugsweise aus Briefen über Gründung und Dotierung des Bistums, aus Privilegien der haiser und Päpste, aus Dokumenten der dem Bistume zugewiesenen Stifter und Klöster, vor Allem auch aus den Domkapitel-Statuten und einigen alten Kopialbüchern bestanden haben. Erst aus späteren Aufzeichnungen lässt sich mit Sicherheit entnehmen, dass Archiv sowohl als Domschatz der Obhut von zwei Mitgliedern des Domkapitels anvertraut waren, die man, weil sie die Schlüssel zu dem Sakrarium in Verwahrung hatten, kurzweg die Schlüsselherren nannte. Wenig genug mag diese Herren des hohen Kapitels die Sorge um Ordnung und Verzeichnung des Archivs angefochten haben, stammt doch das älteste Repertorium, das Registrum generale, erst aus der Mitte des 15. Jahrhunderts. Und wenn in früherer Zeit an ein System in der Aufstellung und Einteilung der Archiv-Bestände überhaupt nicht zu denken gewesen, möchte auch diese erste im Registrum generale zutage tretende Ordnung an Einfachheit gewiss nichts zu wünschen übrig lassen. Die Gruppierung ist nämlich folgende:

1. Kaiserliche Privilegien und von der Gründung des Bistums. A.

2. Fäbstliche Privilegien. B.

3. Güterschenkungen. C.

4. Urkunden der Dompropstei. D.

5. Alte Kapello Regensburg. E.

6. Abteien und Klöster. F.

7. Statuten des Domkapitels. G.

8. Dom-Obleien und Fragrnente. H.

9. Testamente. I. 
10. Inlässe, Aussprüche und Urteile über die Stadt-Munitäten. K.

11. Lingeld, Tatz und Steuer. L.

12. Urkunden des Domkapitels. II.

13. Domprädikatur. N.

14. Amt des Subkustos. O.

15. Litterae pertinentes ad Episcopun. P.

16. Urkunden ïher Mass und Ciewicht, Quittungen und alte Kautionen. Q.

17. Urkunden der Dom-Vikarier. R. S. T. U. V.

18. Urkunden über das Werkamt. ${ }^{1)} \mathrm{Z}$.

Gruppe Nr. 10: "Litterae ad Episcopum pertinentes" veranlasst mich zu der Feststellung, dass ein eigenes bisch öfliches Archiv zu jener Zeit noch nicht existierte, oder wenigstens nicht als selbständiger Teil aus dem, sagen wir, 1)omstifts-Archiv ausgeschieden war. Gleichwohl muss schon bald zwischen zwei auch räumlich getrennten Archiven unterschieden werden, dem Domkapitelschen mit seinen ungleich älteren und wichtigeren Beständen, das nach wie vor im Sakrarium des Domes lagerte, und dem fürstbischö flichen, das in der alten "Hofhaltung", wie der an der Nordseite des Domes befindliche ausgedehnte Gebiude-Komplex noch heute genannt wird, untergebracht war und daselbst beim Ausgange des 16. Jahrhunderts neben den Kanzleigelassen schon drei Gewölbe füllte.

Dieses letztere Archiv, das sich von dem Domkapitelschen hauptsächlich deswegen trennte, weil es infolge des bei allen bischöflichen Hof- und Landesstellen immer breiter sich entwickelnden Aktenwesens zu sehr an Jimfang gewann, als dass es bei den Raumverhältnissen des Sakrariums noch weiter Platz daselbst hätte finden können, setzte sich zunächst aus den Duplikaten aller älteren Uıkunden und den Lehenarchivalien, später auch aus den Reichs- und hreistagsverhandlungen, den Gerichtsund Verwaltungsakten, dem verschiedensten Rechnungsmaterial u. s. w. zusammen.

Gleich hier soll erwähnt werden, dass Jahrhunderte lang das Bamberger Archiv die Quelle ununterbrochener heftiger Konflikte und Kämpfe zwischen Bischof und Lomkapitel gewesen ist, da letzteres auf sein nicht gerade ausschliessliches, aber doch

1) Werkamt-Dombauamt. 
vorzugiveises Anrecht auf das eigene Archiv, wie das des Bischofs, in keinerlei Weise zu verzichten gewillt war, während die Fürstbischöfe stets darauf bedacht gewesen sind, das ganze hochstiftische Archiv, dessen wichtigster Teil, wie schon ifter bemerkt, im Segerer des Domes lag, allmählich in ihre Gewalt und Verwahrung zu bringen. Dieser hartnäckige, erbitterte Kampf um das uneingeschränkte Verfügungsrecht über das seiner ganzen Natur und Bestimmung nach doch beiden 'Teilen gemeinschaftliche Archiv hat seinen Abschluss erst dann gefunden, als auch die 'Tacre des Bistums als geistlicher Staat bereits gezählt gewesen sind; er hängt auf das innigste mit der Entwicklung der Gesamtverhältnisse im Bistum zusammen. Wie an manch anderem deutschen Hochstifte bestand auch hier zwischen Bischof und Kapitel ein stetiges gegenseitiges Ringen um Erweiterung ihrer speziellen Machtbefugnisse, ein Wettstreit, der seinen Ausdruck in jenen Wahlkapitulationen fand, die vom Kapitel jedem neuen Bischofe zur Beschwörung förmlich aufgedrängt worden sind.

Die ständigen Wahlkapitulationen sind in Bambergerst in 15. Jahrhundert - die älteste eigentliche Kapitulation datiert aus dem Jahre 1422 -- aufgekommen.

Seit Anfang des 16. Jahrhunderts schwollen dieselben immer mehr an und überboten im Laaufe der Zeit an Umfang und Kühnheit der $\Lambda$ nsprüche jene von Würzburg, woselbst durch einmütiges Vorgehen von Kaiser und Papst die Kraft der Kapitulationen in der zweiten Hälfte des 17. Jahrhunderts gebrochen worden ist. Papst Innocenz XII. erliess nämlich im September 1695 eine Bulle -- Constitutio Innocentiana -, welche unter Androhung der schwersten Kirchenstrafen dem Doinkapitel in Würzburg jede verpflichtende Abmachung vor der Wahl eines Bischofs verbot und die päpstliche Bestätigung für die etwa nach der Wahl vorgelegten Verträge verlangte.

Lothar Franz von Schönborn (1693-1729) liess diese Constitutio, welche Kaiser Leopold I. mit Reskript vom September 1698 ausdrïcklich gutgeheissen hatte, auch in Bamberg im Peremptorium des Kapitels zur Verlesung bringen, vermochte damit aber nicht die geringste Wirkung zu erzielen. Das Bamberger Kapitulationswerk hatte damals seinen Höhepunkt erreicht und die Kapitulation war zu einem Buche mit weit über hundert 
Artikeln angewarhsen. Der Neffe und Nachfolger Lothars Franz, Friedrich Karl ron schönborn (1i29) bis 1i+6) war aber der rechte Mann dazu. die Sondergewalt des Kapitels herabzudı ücken und den Kapitularen die fürstliche Machtstellung zum Bewusstsein zu bringen. schon als Coadjutor seines Onkels verweigerte er 1708 beharrlich die Lnterzeichnung einer Kapitulation und verstand sich auch nicht dazu, als er in Jahre 1729 zur Regierung berufen wurde.

Die Kapitulationen stellten gewissermassen die rechtliche Verfassung der Bistümer dar. In Würzburg erfuhren sie zu gunsten des Fürsten durch die Intervention von Kaiser und Papst eine Umgestaltung. während in Bamberg der Bischof sich sellbst zu helfen wusste, indem er durch rücksichtslose Anwendung der ihm zu Gebote stehenden Gewalt die Privilegienwirtschaft des Kapitels durchbrach und infolgedessen die rechtliche Veränderung im Kapitulationswerk anbahnte. ${ }^{1}$ )

Um auf die Ordnung und bessere Organisierung des Archivs zurückzukommen - wir haben bisher ja nur von einem einzigen sogenannten Repertorium, dem Registrum generale gehört -, so ist ror allem ein Beschluss des Domkapitels rom 2. August 1505 geeignet, unser Interesse zu erregen, der dahin gelautet hat: ,eine Ordnung vorzunehmen der Briefe halber, einem Kapitel und den Vikarien zuständig“. Ueber das Wesentliche dieser Archivordnung näheren Aufschluss zu geben, fehlt uns leider jedweder Anhaltspunkt; nur so viel ist bek annt, dass 1. ohne Rekognition niemand, nicht einmal der lompropst, ja selbst der Fürstbischof nicht, irgend ein Stück auıs dem Domsegerer herausbekommen solle und 2. dass alles, was seiner Natur nach ins Archiv gehöre, auch dahin abgreliefert werden müsse. Letztere Bestimmung erscheint von besonders tief einschneidender Bedeutung; lässt sie doch ein lebhafteres Interesse an der weiteren Entwicklung des Bamberger Archivwesens, ein tieferes Verständnis für die Grundbedingungen einer planmässigen, zielbewussten Ausgestaltung desselben unschwer erkennen.

1) Wild K. Staat und Wirtschaft in den Bistümern Würzburg und Bamberg (Heidelberger Abhandlungen zur mittleren und neueren Geschichte) $1906 \mathrm{~S}$. $14 \mathrm{ff}$. Vgl. auch Looshorn, Geschiohte des Bistums Bamberg, Bd. II S. 587 , Bd. III S. 147, 150, 507, Bd. IV S. 10, 181, 225, 300, 339, 388, 437. $451,456,544 \mathrm{ff}$. 
Sun sind leider die ruhigen Tage für unser Archiv auf lange Zeit hinaus vorüber: ein wechselvolles Schicksal ist ihm beschieden: Feindesgefahr zwingt es, durch häufiges Flüchten ron einem Ort zum andern, zum Teil in weite Ferne, sich zu retten: Bauernaufruhr und markgräfliche Fehden, dreissigjährige Kriegrsnot und Einfälle preussischer Truppen während des Siebenjährigen Krieges in das Hochstift stürzten es unaufhörlich in schwere, verderbliche Krisen.

Die in der Bischofsresidenz, in der Hauptstadt des Hochstifts beginnenden Lnruhen. welche dem Bauernaufruhr - unterstützt von Bambergs Bürgern - vorangegangen sind, veranlassten Bischof und Kapitel, das Gesamtarchiv in seinen älteren und wertvolleren Beständen auf das fürstbischöfliche Schloss, die Altenburg, in Sicherheit zu bringen. Es verblieb daselbst ron 1522 bis 1553 , in welch letzterem Jahre Markgraf Albrecht Alcibiades auf seinem Verwüstungszuge durch die fränkischen Lande die Stadt Bamberg eroberte, die Altenburg zerstörte und das Archiv auf seine Feste Plassenburg verbrachte. Wenn es daselbst auch nur kurze Zeit - etwas länger als ein Jahr Unterkunft fand und bereits im August 1554 die von Kaiser und Reich gleich lebhaft geforderte Rückgabe erfolgte, hatte es doch, wie aus den nachgelassenen Papieren des späteren Plassenburger Archivars Ph. E. Spiess festzustellen ist, durch Plünderung arge Verluste erlitten. Uebrigens kehrte es nicht direkt in die Stadt Bamberg, die volle Sicherheit noch immer nicht bot, zurück, sondern wurde von der Platssenburg weg nach dem inzwischen stärker befestigten lorchheim und erst 1570 wieder an seinen heimatlichen Standort, nach Bamberg, transferiert.

Diese Zurückversetzung bildet gewissermassen einen Markstein in der Geschichte des Archivs, indem gelegentlich derselben nicht bloss alle jüngeren, die Fürstbischöfo direkt beteffenden Schriftstïcke in die bischöfliche Hofhaltung wanderten und forthin dort verblieben, sondern auch ältere Lehenarchivalien, Reichs- und Kreistagsakten u.s. w. zurückbehalten wurden, womit die förmliche Scheidung in ein domkapitelsches und ein bischöfliches Archiv vollzogen worden ist. Diese grundsätzliche Trennung, die als Ergebnis einer zugunsten des Bischofs ausgefallenen Kraftprobe zwischen diesem und dem Kapitel sich erweist, und bei der dem Archive des letzteren in der Hauptsache nur mehr 
das auf die Gründung und Dotierung des Bistums bezügliche Urkundenmaterial, die Domkapitelstatuten, die Dompropsteiurkunden sowie jene der Obleien und Fragmente, der Domprädikatur, Subkustodie u.s. w. gewahrt blieben, hat erst 1803 mit der Säkularisierung bzw. Mediatisierung des Fürstentums Bamberg ihr Ende gefunden.

Die bedenkliche Unordnung und Verwirrung, in welehe beide Archive durch die wiederholten Flüchtungen und Verschiebungen notwendigerweise geraten mussten, führte nach Zurückverbringung derselben in den Domsegerer bzw. in die bischöfliche Hofhaltung zu einer durchgreifenden Umarbeitung der obengenannten Repertorien, zu welchen noch zwei auf der Altenburg und in Forchheim während der Verbannung gefertigte, das ganze Hochstift umfassende zu zählen sind, nämlich: „Inventarium brieflicher Urkunden zu fürstlicher bambergischer Cantzelei gehörig“, sowie: „Directorium vnd Verzeichnus aller vnd Jeder in den Raistruhen verwarter vnd zusammengenrdneter brieflicher Urkunden".

Nach wenigen Jahren schon entstand das sogenannte zweite alte Directorium, ein äusserst unfangreiches, das gesamte vorhandene Material in folgende 42 grössere Gruppen scheidendes Repertorium: 1. Privilegia, kaiserliche und königliche, ron 1097 an. 2. Canonisationen von 1008 an. 3. Geistliche Jurisdiktion von 1008 an. 4. Päpstliche Bullen von 1008 an. 5. Empfängnis des Stifts Regalien und Weltlichkeit ron 1039 an. 6. Ionationes von 983 an. 7. Statuta von 1113 an. 8. Herrschaft Kärnthen von 1176 an. 9. Steuern ron 1334 an. 10. Zölle von 1396 an. 11. Centgericht von 1376 an. 12. Münzwesen von 1354 an. 13. Tat\% und Ungeld von 1338 an. 14. Gemeine Kaufbriefe, die von keinem Bischofe herrühren, von 1339 an. 15. Gemeine Reverse und Obligationen von 1315 an. 16. Kaufbriefe der Bischöfe vou 1017 an. 17. Erbämter der Kurfürsten von 1269 an. 18. Hof zu Regensburg von 1417 an. 19. Lehenmachung und andere Lehensachen von 1248 an. 20. Stadtgericht und Munitäten von 1261 an. 21. Gemeine Pfaudschaften von 1359 an. 22. Pfandschaften der Bischöfe von 1246 an. 23. Wiederlösungen seitens der Bischöfe von 1243 an. 24. Verträge, Anlass- und Urteilsbriefe, das lomkapitel betr., von 940 an. 25. Ditto, die Bischöfe betr., von 1129 an. 26. Zwietracht zwischen Bischöfen, Domkapitel und Stadt von 1330 an. 2i. Klöster 
in und alsser Bamberg ron 485 an. 28. Aufruhr, Fehden und Kriegs:achen von 1378 an. 29. Einigungen und Bündnisse von 1315 an. 30. I)iversa von 137: an. 31. Kaufhriefe, einem Domkapitel zustiundig, von 1148 an. 32. Zinsbriefe ron 1346 an. 33. Cantoreigüter ron 1256 an. 34. Dompropstei ron 1336 an. 35. Kustoreigüter von 1298 an. 36. Ant Staffelstein von 1165 ail. 37. Jahrtags-Stiftungen von 1377 an. 38. Dom-Fragmente von 1398 an. 39. Prädikatur von 1364 an. 40. Dom-Obleien von 1271 an. 41. Scolasterie von 1327 an, endlich 42. Alte Kapelle 2u Regeusburg von 848 an.

Es dürfte wohl sicher die Kunde erhöhtes Interesse bieten. dass diese aus dem Jahre 1575 stammende Archiv-Ordnung noch bei Aufhebung des Bistums, 1803, im grossen und ganzen das System gebildet hat, nach welchem - von wenigen Zusätzen und Erweiterungen abgesehen - das bambergische Archiv aufgestellt und eingeteilt gewesen ist.

In den folgenden 50 Jahren scheint sich niemand mit einer nennenswerten Repertorisierungsarbeit beschäftigt zu haben; erst aus dem Jahre 1629 ist ein weiteres Repertorium, richtiger Kopialbuch, zu vermelden, das seiner ganzen Anlage und Durchführung nach als eine mustergültige Leistung sich erweist. Der uns unbekannte Verfasser hat nicht allein von sämtlichen Urkunden des domkapitelschen Archivs Regesten angefertigt und ein Abbreviaturen-Verzeichnis hergestellt, sondern zum Schlusse auch Abschriften der Urkunden selbst mit ungewöhnlicher diplomatischer 'Treue und Genauigkeit folgen lassen.

Wiederum kommen schwere Tage für das Bistum, die an alles, nur nicht an ruhige Arbeit in den Gewölben des Domsegerers oder in den Kanzleigelassen der fïrstlichen Hofhaltung denken liessen. Mehr und mehr zogen sich die Schrecknisse des IPreissigjührigen Krieges in die Nähe des fränkischen Lreises und des kaiserlichen Hochstiftes Bamberg und zwangen Bischof und Kapitel abermals, Massnahmen zur Sicherung und Rettung von Domschatz und Archiv zu treffen. Anfang November 1631 lagerten beide bereits in den Hallen des Zisterzienserklosters Niederaltaich an der Donau, konnten aber, da die Feindesgefahr von Böhmen her auch dem bayerischen $W$ alde sich näherte des Klosters Schutz und Frieden nur kurze Zeit geniessen. Nach wenigen Wochen schon ruhten Archivbestände und Dom- 
heiligtümer in den festen Gewölben des fürstbischöflich Bambergischen Schloses Wolfsherg in Kärnthen. Vehr als ein Jahrzehnt hat dort das Gesamtarchiv sichere linterkunft grefunden und erst 1642 ist es nach Bamberg zuriuckgekehrt. freilich nur, um kurze Zeit darauf wiederholt die lange Wanderung nach dem hochfürstlich Bambergischen 'Trile des Herzogtums Kärnthen anzutreten, da abrmals feindlirhes Heere, diesmal Franzosen und Weimarsche 'Truppen, gegen das schwergeprüfte Hochstift sich zogen. 1651 hatte dieses zweite unfreiwillige Herbergen in dem sicheren Alpenlande sein ersehntes Ende gefunden.

30 Jahre später (1682) ist wiederum eine archivalische Leistung: „Repertorium über die in eines Donkapite's des hohen Stiffts Bamberg Registratur befindlichen Lrkunden. worinnen nicht allein das Domkapitel, sondern anch das ganze Hochstifft sonderbar mit interessiert u. $s . w . "$, zutage getreten, welche jedoch das bescheidenste Mass archivalischen könnens gründlich vermissen lässt und derartig laienhaft und unzulänglich ausgefallen ist, dass sie dem trefflichen Repertorium von $15 \pi$ gregenüber $\mathbf{z w e i f e l s o h n e ~ a l s ~ b e d e n k l i c h e r ~ R u ̈ r k s c h r i t t ~ a u f ~ d e m ~ G e b i e t e ~ d e s ~}$ Bamberger Repertorisierungswesens zu bezeichnen ist.

Ungleich wichtiger erscheint die Tatsache, dass ungefähr zur selben Zeit (1690) neben dem fürstbischöllichen Archive eine eigene Registratur für die bischöfliche Kabinettskanzlei sich hildete, deren Hauptbestandteil die sogenannten Kabinettsakten waren, wozu man namentlich die Reichs und Kreistagsakten, Münzakten, Hofkammer-. Hofrats-, Syndikats-, (H)ereinnahmeu. s. w. Akten rechnen muss.

Diese Geheimregistratur, wie man sie kurzweg geheissen. wurde - um gleich hier davon zu reden - in der Folge als sogenannte Bamberger reponierte Hauptregistratur aus der Hofhaltung in die Kirche des aufgehobenen Karmeliterklosters transferiert, bis $1821 \mathrm{dem}$ in bayerische Ijenste übernommenen ehemaligen hochfürstlich Bambergschen Archivar Uesterreicher unterstellt und 1829), nachdem ihr Oesterreicher alle von ihm als streng archivalisch befundenen Stücke entzogen und seinem Archive einverleibt hatte, an die k. Regierung des Obermainkreises in Bayreuth überwiesen.

Noch immer waren die Tage ruhelosen Wanderns und 
Flïchtens für das domkapitelsche wie fürstbischöfliche Archiv nicht qrezählt. Während der alte Streit zwischen beiden Archiven, der schon so häufig in die Erscheinung getreten, tobte und der bischöfliche Archivarius Christoph Balthasar Faber es war. der von neuem einer durchgreifenden Ausscheidung der im domkapitelschen Archive lagernden Urkunden und Akten, soweit sie "immediate" den jeweiligen Fürstbischof beträfen, gar eindringlich das Wort redete, brach der siebenjährige Krieg aus, und man hatte alle Mühe, noch vor Torschluss beide Archive nebst den Kirchenschätzen nach Würzburg auf die Feste Marienberg und ron da nach Mainz zu verbringen. Mitte April des Jahres 1763 wurde mit dem Rücktransport nach Bamberg begonnen, das man auch nach mehreren Monaten, - 14. Juli glücklich wieder erreichte. Für den tüchtigen Archivar Faber, welchem wir die Bearbeitung eines neuen Repertoriums: „Ueber das hochfürstlich-bambergische Archiv (I. Teil)" verdanken, ist diese Flüchtung freilich verhängnisvoll geworden; sie brachte ihm frühzeitigen Tod, nachdem er sich auf der Fahrt nach Mainz ein "hitziges Fieber" zugezogen hatte.

Endlich sind sie vorüber, die Zeiten allzu häufiger Beunruhigung, Gefährdung und Bedrohung unserer beiden Archive. Bereits im Jahre 1750 hielt das eine, das des Bischofs, seinen Einzug in die schon von Haus aus zur Aufnahme seiner Bestände ausersehenen schönen Hochparterre-Räume des durch Dienzenhofer neuerbauten prächtigen Residenzschlosses ..- vollständig losgelöst von der in der bischöflichen Hofhaltung zuräckgebliebenen geheimen Registratur, bereichert jedoch durch die älteren Urkunden des Vikariats, dessen langjähriger Widerstand gegenüber der Weisung, dieselben in das Archiv abzuliefern, endlich vom Bischofe Adam Friedrich von Seinsheim (1157 bis 1779) gebrochen worden ist. Auch das seit längerer Zeit schon neuentstandene sogenannte Kreisarchiv, in welchem, da Bamberg neben Brandenburg-Culmbach mitausschreibendes und zugleich Direktorial-Mitglied des fränkischen Kreises gewesen, zunächst die Kreisdirektorialakten ${ }^{1}$ ) Aufnahme fanden, hat nun

1) Mehr als 500 Faszikel Bamberger Provenienz wurden merkwürdigerweise im Jahre 1882 nach Nürnberg extradiert! Vgl. Fester, Neujahrsblätter der Gesellschaft für Fränkiscbe Geschichte: „Franken und die Kreisverfassung." 1906, pag. 7 und 57. 
einen integrierenden Bestandteil des bischöflichen Archivs gebildet, wie z. B. dessen Personalstand aus den Jahren 1767, 1769) und 1800 zur Genüge erkennen lässt.

Bischof Adam Friedrich ron Seinsheim, dessen eben Erwähnung geschah, war in ungleich höherem Masse als irgend einer seiner Vorgänger um das schöne Bamberger Archiv besorgt, das er 1763 auf das eingehendste besichtigte. Rasch hat te sein scharfer Blick erkannt, dass vor allem eine Personalvermehrung zur Bewältigung der Archiv-Arbeiten eintreten müsse; zwei Tage nach erfolgter Besichtigung wurde denn auch durch hochfürstliches Dekret vom 24. November 1763 die Anstellung und Verwendung von zwei neuen Beamten, sogenannten Registranten verfügt.

Berufs- und arbeitsfreudige Männer der Wissenschaft und praktischen Erfahrung, voll von Hingebung an den archiralischen Dienst mit seinen vielgestaltigen Pflichten und dufgaben, machten sich in der folgenden Zeit bis zur Säkulasierung des Bistums und dem Uebergange des Fürstentums an die Krone Bayern um die Bamberger Archive in hohem Grade verdient. Der noch heute wegen seiner von ungewöhnlich feinem Kunstsinn und ausserordentlich geläutertem (ieschmacke zeugenden Bautiatigkeit ${ }^{1}$ ) in allen Schichten der Bamberger Bevölkerung vielgenannte Hofrat und Archivar Boettinger, insbesondere aber sein Nachfolger $J_{O s .}$ Albin Kluger, haben sich durch ihre erfolgreiche, vorzugsweise auf organisatorisehem Gebiete gelegene Tätigkeit den Dank und die Anerkennung ihres Fürsten gesichert. Von Klugers Arbeiten, der „obschon kein ausbündiger Jurist doch sonsten ein gutes studium, eine lesbare Handschrifft, eine Käntnis aller schrifften, eine Wissenschaft archivalischer Verrichtungen und vitam sedentariam, indefessam et agilem" hatte, ist zunächst sein ganz vortrefflicher "Elenchus Codicum Constitutionum Bambergensium* hervorzuheben, den er über 14 mit hochfürstlichen Verordnungt!n des verschiedensten Inhalts. angefüllte Foliobände gefertigt und am 4. März 1775 Serenissimo unterbreitet hat. Vergessen soll dann nicht werden seine Geschichte des Fürstbistums Bamberg in neun Foliobänden, obwohl sie mehr ein Panegyricus der Fürstbischöfe zu nennen und eben im Geschmack jener Zeit bear-

') Siehe Prellshaus und Konkordia. 
beitet worden ist. Bedeutendes leistete ferner der im Jahre 17i2 neben Kluger zum $z$ weiten Archivar ernannte Wilhelm Johann Heyberger, mit dem zweifelsohne ein sehr geniales, aber auch höchst unruhiges Element in die Erscheinung tritt. Das von ihm 1775 ausgearbeitete „Systema Archivi Secretioris Principatus Bambergensis" darf mit vollstem Rechte als ein förmliches Generalrepertorium über das ganze fürstbischöfliche Archiv bezeichnet werden, dessen Wert noch dadurch wesentlich sich erhöht, dass es als lotzte Arbeit gilt, welche in solcher Weise hergestellt worden ist und von dieser Art sich erhalten hat.

Die stattliche Reihe der Archivare des Fürstbistums Bamberg schliesst mit Paul Oesterreicher ab, dessen Name, um mit Häutle zu reden, in den Annalen der gelehrten Welt einen guten, ja vorzüglichen Klang hat. Er trat am 18. November 1801 neben dem körperlich wie geistig alternden Kluger seine Stelle an und ging 1803 mit dem Archive selbst in bayerische Dienste über, in welchen er bis zu seinem Tode - 1839 - rastlos und erfolgreich tätig gewesen ist.

Den zw eiten grossen und wichtigen Bestandteil des beutigen Kreisarchivs,

\section{das sogenannte Plassenburger Archiv}

anlangend, mag vielleicht Folgendes einige Beachtung finden und verdienen.

Als in der Mitte des 14. Jahrhunderts die Burggrafen von Nürnherg ihren stetigen Sitz auf der durch die meranische Erbschaft mit der Stadt Culmbach neuerworbenen Feste Plassenburg aufgeschlagen hatten, verbrachten sie dahin gleichzeitig ihren der Zahl nach noch geringen Vorrat an Privilegien-, Lehenund anderen Briefen. Auch nach Belehnung Friedrichs VI. mit der Mark Brandenburg durch Kaiser Sigmund, 1417, ja selbst als das markgräfliche Haus in mehrere Linien sich gespalten hatte, ist jenes Stamm-Archiv infolge einer Bestimmung des Markgrafen Albrecht Achilles als ge meinsames FamilienEigentum unverrückt an seinem Platze geblieben. Mit dieser weisen Bestimmung dokumentierte der zu den erleuchtesten Reichsfürsten zählende grosse Brandenburger zweifelsohne ein hohes Interesse an dem Archive, ein seltenes Verständnis für die Bedeutung und den Wert eines solchen, einen stark aus- 
geprägten historischen Sinn, und es kann gleich hier nicht laut genug betont werden, dass zu allen Zeiten das Plassenburger Archiv sich einer besonders wohlwollenden Würdigung und Fürsorge seitens der Markgrafen erfreuen durfte, dass seine Verwaltung eine äusserst verständige, zum guten Teil rein fachmännische gewesen und seine leitenden Beamten im Gegensatz zu jenen des fürstlich Bambergischen Archivs in verhältnismässig hohe Rangstellungen einrücken konnten.

In den ersten Zeiten ist unser Archiv der Obhut des jeweiligen Landschreibers, ,auf dem Gebirg“, i. e. „des Burggrafentums Nürnberg oberhalb Gebirgs", anvertraut gewesen. In seinem Diensteide ist daher auch der Passus zu finden: „Ich glob und schwer, das ich vleissigs aufsehen haben will, damit irer gnaden lehenbuchern, schuldbuchern, reigistern. briven, privilegien und missiven kainerlai beschedigung zugefugt, noch doraus oder daran einicherlai abschrift niments gegeben werde on irer gnaden wissen und willen."

Der Landschreiber war das wichtigste Organ der Regierung und bekleidete die höchste Würde, die ein Bürgerlicher damals überhaupt erreichen konnte. Auf seinen Schultern ruhte die eigentliche Geschäftslast, ohne sein Vorwissen und seinen Rat durfte der „Hauptmann auf dem Gebirg ", welcher der ritterliche Repräsentant der Regierungsgewalt gewesen, nichts unternehmen, ohne ihn konnto keine dusfertigung erfolgen, weil er das Siegel verwahrte. Alle Personen der obergebirgischen Kanzlei mussten dem Landschreiber bei ihrer Verpflichtung Gehorsam geloben. An ihn hatten die fürstlichen Aemter und Renteien ihre Zinsen, Steuern und die übrigen Gefälle abzuliefern, durch ihn gingen alle Ausgaben, er visitierte die Aemter und war endlich auch der Lehenpropst. ")

Von den ersten sechs, mit der Leitung des Archivs betrauten Landschreibern ist nicht bekannt, dass sie in irgend einer Weise archivalisch sich betätigt hätten; erst der siebente und zugleich letzte unter dem Markgrafen Friedrich (1486-1515) als Vorstand des Archivs fungierende Landschreiber Prucker muss hier rühmlichst hervorgehoben werden. Von ihm ist näm-

1) K. H. Lang, Neuere Geschichte des Fürstentums Bayreuth, I. Teil von 1486 bis 1527 . S. 26 und F. Wagner, Kanzlei- und Archivwesen der Fränkischen Hohenzollern. Archiv. Zeitschrift Bd. X S. 33 u. 34. 
lich 1499 das: noch jetzt im Kreisarchive Bamberg vorhandene "Landbuch über die Aemter Bayreuth, Creussen und Frankenberg", bekannt als rine der ältesten und schätzenswertesten unter den gleichartigen Aufzeichnungen, hergestellt worden. Eine förmliche Organisation erfuhr das Archiv jedoch erst durch den Nachfolger Pruckers. durch Erhard Frankenberger, der als Propst i. e. Vorstand der Hofkirche und Verwahrer der Hausreliquien und Heiligtümer auf der Plassenburg infolge der Reformation liatte resignieren müssen und dann 1526 , al s Archivar in dem Gewölb zu Plassenburg a angestellt worden ist. 1534 erhielt dieser erste eigentliche Archivarius durch den Markgrafen Georg ,eine gemessene Instruktion, wie das Inventarium über die Plassenburgsche Registratur angefertigt werden solle", da ein Repertorium bis dahin noch nicht vorhanden war. Frankenbergers Arbeiten .. ein umfangreiches, fünfbändiges "Inventarium über das ehemalige sogenannte Gewölb, nunmehr geheime Archiv zu Plassenburg “, sowie ein kleineres Repertorium über das die Reichsstadt Rothenburg ob der Tauber betreffende Urkundenmaterial - sind ebenfalls heute noch im k. Kreisarchive Bamberg vorhanden. Das fünfbändige Inventar erscheint als ein systematisch angelegtes Werk, dessen I. Band die Urkunden des Oberlandes von 1250 bis 1540 behandelt, während die vier weiteren Tomi die Dokumente des Unterlandes von 1259 bis 1529 verzeichnen. Jedwedes System lässt dagegen das ron 1316 bis 1550 reichende Reportorium über den Rothenburger Urkundenbestand rermissen.

Eine weiiere Förderung der durch Markgraf Georg 1534 ernstlich anbefohlenen Ordnungsarbeiten geriet durch den Ausbruch des markgräflichen Krieges. in specie durch die Belagerung Plassenburgs seitens der gegen den Markgrafen Albrecht Alcibiades verbïndeten Stände Würzburg, Bamberg und Nürnherg in völliges Stocken. Nach Eroberung und Schleifung der Feste 1554 wurden die in Kisten verpackten Archivalien entgegen den klaren und bestimmt gehaltenen Kapitulationsbedingungen von der Reichsstadt Nürnberg heimlich weggeführt, unterwegs aber von dem Bischof von Bamberg in Forchheim angehalten, der sie als Repressalien für die durch Albrecht Alcibiades erlittenen Schäden gebrauchen wollte. Ueber die Rückgabe des widerrechtlich weggenommenen Archivs waren 
die Verhandlungen des markgräflichen Hauses mit den Bundesständen Würzburg, Bamberg und Nürnberg zu Rothenburg ob der Tauber 1554 gänzlich erfolglos; erst nach dem Regensburger Reichstagsabschiede 1556 hat die Angelegenheit ihre Erledigung gefunden. Auf neun Wagen wurden die Archivbestände nach Bayreuth verbracht und daselbst in Oktober 1556 in dem gleichen Zustand, in dem sie zwei Jahre vorher von der Plassenburg abgeführt worden waren, in $z$ wanzig kleinen und grossen Fässern, sieben grossen und kleinen Truhen und zwei kleinen Lädlein verpackt und versiegelt dem markgräflich brandenburgischen Kommissär harl Ezel übergeben.

Als dann 1557 das Oberland, i. e. das Markgrafentum Brandenburg-Bayreuth-Culmbach, das nach dem Falle Plassenburgs 1554 von den Bundestruppen in Besitz genommen und 1556 dem Grafen Joachim Schlick zu Bassaun als kaiserlichem Sequestrations-Kommissär übergeben worden war, nach dem Tode des kinderlosen Albrecht Alcibiades dem Markgrafen Georg Friedrich von Ansbach (1557 bis 1603) zufiel und somit die beiden fränkischen Fürstentümer wieder vereinigt wurden, hat man die Ordnungsarbeiten im drchive wieder aufgenommen, dieselben aber wegen Mangel an tüchtigen, brauchbaren Kräften längere Zeit nicht wesentlich zu fördern vermocht. Erst in dem als Verfasser einer Genealogie seines Fürstenhauses bekannten Arzte Johann Moninger wurde die geeignete Persönlichkeit gefunden, die mit Eifer und Verständnis an die Ordnung des Archivs herantrat und ein Repertorium in vier Foliobänden lertigte, das noch heute einen mitunter recht schätzenswerten Notbehelf bietet, wenn auch sein praktischer Nutzen bei den jetzt vorhandenen neuen Repertorien nicht besonders hoch eingeschätzt welden darf. A us den Arbeiten Moningers läist sich übrigens entnehmen, dass unter der Regierung des genannten Markgrafen Georg Friedrich aus dem ursprünglichen $\mathrm{Hausarchiv}$ auf der Plassenburg allmählich sich ein förmliches Landesarchiv herausgebildet und als solches weiter entwickelt hat.

Da der Sitz der Regierung nach Vereinigung der Fürstentümer von der Plassenburg nach Ansbach, der Residenz Georg Friedrichs, verlegt worden war, musste naturgemäss auch eine beträchtliche Anzahl Archivalien nach der Hauptstadt des Unterlandes transferiert werden. Diese Vermengung und Verschlep- 
pung ron Archivteilen hatte, besonders nachdem 1603 die vereinigten Fürstentümer wieder getrennt wurden und bis 1769 auch getrennt blieben, die beklagenswertesten Missstände im (iefolge, und es mussten zu den verschiedensten Zeiten, so 1603 und 1604, 1625, 1629, 1684, 1703, 1709, 1714 und 1738, alle nur möglichen Schritte unternommen werden, um eine gründliche Ausscheidung der Archivalien, welche in Ansbach zu verbleiben hatten und welche wieder auf die Plassenburg zurückzuleiten waren, herbeizuführen.

Eine nachhaltige und besonders tief einschneidende Verbesserung hat das Plassenburger Archivwesen unter dem Markgrafen Christian Ernst (1650 bis 1712) erfahren, der seine Residenz nach Bayreuth verlegte und den bisherigen Hofmeister v. Brunnwasser 1658 zum Archivar bestellte. Dieser verdienstvolle Leiter des Archivs - Schwiegersohn des berühmten kaiserlichen Rates Christoph Agricola - unterzog die sogenannte Culmbacher Kanzleiregistratur, welche fast die ganze Masse von Archivalien aus der zweiten Hälfte des 16. und dem Anfange des 17. Jahrhunderts enthielt und bei ihrer Uebersiedlung nach Bayreuth, dem nunmehrigen Sitze der oberländischen Regierung, durch Verkauf eines grossen Teils von Material an die Krämer von Culmbach stark gelitten hatte, einer gründlichen Sichtung, nahm einen erheblichen Teil von Urkunden und Akten in das Archiv als dorthin gehörig auf, und wusste zugleich seinen fürstlichen Herrn für eine wesentliche Vermehrung des Personals zu gewinnen.

Ein wirklich wissenschaftlicher Geist begann sich jedoch erst unter der Verwaltung des 1747 zum Hofrat und ersten Archivar ernannten früheren Stadtsyndikus und Prozessrates Johann Jakob Will zu regen. Auch von ihm sind noch zwei geradezu mustergültige Repertorien in vier bezw. fünf Bänden, von welchen das grössere über die Lehenbriefe und Reverse des Fürstentums oberhalb Gebirgs - nach Geschlechtern geordnet - besonders hervorzuheben ist, im Kreisarchive Bamberg vorhanden.

In ungleich höherem Masse als alle bisher genannten Plassenburger Archivare ist der Hof- und Regierungsrat Philipp Ernst Spiess, ,vorderster geheimer Archivar auf der Plassenburg “ bei Ordnung und Bearbeitung des archivalischen Materials 
nach einem streng wissenschaftlichen Plane verfahren. Die Verdienste dieses Mannes un Theorie und Praxis der Archivwissenschaft können ebenso wie seine rastlosen Bemübungen. die im Lande zerstreuten Archivalien aufzusamıneln, nicht hoch genug gewürdigt und eingeschätzt werden Sein eminenter Fleiss, seine glänzenden Erfolge auf allen Gebieten archivalischer Betätigung, die Zahl seiner hinterlassenen Arbeiten sind wahrlich geeignet, gerechtes Staunen zu erregen.

Als 1792 die fränkischen Fürstentümer ober- und unterhalb Gebirgs an König Friedrich Wilhelm II. abgetreten waren, verordnete der dirigierende Minister von Hardenberg, dass sofort alle jene Archivalien, deren njederzeit offenstehende Einsicht für die Verwaltung des Landes von keiner geschäftlichen Notwendigkeit sei, namentlich allgemeine Staats- und Familiensachen" ausgeschieden und verzeichnet werden sollen, um sie dann dem $\mathrm{kgl}$. preussischen Haus- und Staatsarchive einzuverleiben. Eine Zusammenstellung solcher nach Berlin bestimmter Archivalien ist auch wirklich angefertigt, die Extradition selbst aber wegen des Missgeschickes des preussischen Heeres in der Champagne, zum Teil auch wegen des inzwischen $-1794 \ldots$ erfolgten Ablebens des geheimen Archivars Spiess. nicht vollzogen worden. Erst auf Grund des Artikels XII des Friedensvertrages Bayerns mit der Krone Preussen rom 22. August 1866 hat eine Auslieferung derjenigen Urkunden und Akten, welchen eine besondere und ausschliessliche Beziehung auf die ehemaligen Burggrafen von Nürnberg und die Markgrafen von Brandenburg fränkischer Linien zukommt, stattgefunden. Das die Verwaltung der fränkischen Lande betreffende Material ist dagegen, was nicht oft genug wiederholt werden kann, von der Ausscheidung und Transferierung nach Berlin vollständig unberührt geblieben.

Spiess' Nachfolger, der 180í in den bayerischen Staatsdienst übergetretene Reichsarchiv-Direktor Ritter von Lang, hat das Plassenburger Archiv der recht unzulänglichen, fragwürdigen Obhut des stets kranken und darum wenig arbeitsfähigen lionservators Liebhard überlassen. Beim Heranrücken von französischen uıd Rheinbundstruppen unter Bernadotte, Soult, Ney und Davout wurde 1806 das ganze herrliche Archiv in Schränke und Kisten verpackt und ist in diesem Zustande -- zur Flucht 
bereit - bis zum Jahre 1813 verblieben. Inzwischen - 1810 war das Fürstentum Brandenburg-Bayreuth an die Krone Bayern übergegangen und das Plassenburger Archiv unter der Oberleitung des $\mathrm{k}$. Reichsarchivs in München dem Bamberger Archirvorstand Oesterreicher, an welchem Konservator Liebhard alle Berichte erstatten musste, zur Verwaltung überwiesen.

Mit dem Jahre 1813 hatte die Oeffnung der Kisten mit den Archivalien begonnen und schon a $\mathrm{m}$ 6. März des folgenden Jahres ist auf Betreiben Oesterreichers eine Entschliessung des k. Staatsministeriums der auswärtigen Angelegenheiten dahin ergangen:

„dass es für nützlich und rätlich befunden wurde, das bisherige Archiv zu Plassenburg nach Bamberg zu verlegen, wo sich ohnehin schon das Hauptkonservatorium (jetziges Kreisarchiv) befindet. Dem Archivar Oesterreicher sind die nötigen Fuhren entweder als Kriegsfuhren oder als in Bayreuth gewöhnlich abzunehmende Scharwerks- bezw. Kammerfrohnen zu gestellen. Zugleich hat der Konservator Liebhard auf der Plassenburg nach Bamberg sich zu begeben und dort als Archivsekretär zu funktionieren."

Erst nach sechs Jahren ist es gelungen, das allerdings schwierige und verantwortungsvolle Geschäft des Umzugs zum Abschluss zu bringen; an 26. Dezember 1818 konnte Oesterreicher an seine vorgesetzte Stelle berichten, dass nunmehr die letzte Fuhre mit 18 Kisten Archivalien in Bamberg eingetroffen ist.

Das alte, musterhaft geordnete und verwaltete, überreiche Plassenburger Archiv hat aber beklagenswerterweise nur verstümmelt seinen Einzug in das hiesige Residenzschloss zu halten vermocht. Durch die leidigen Kriegsverhältnisse in völlige Verwirrung geraten und ausser allem Zusammenhang gebracht, hat es auch bei seiner Rekonstruierung und förmlichen Neubildung dank den hiebei ausschlaggebend gewesenen Gesichtspunkten und nicht zum mindesten durch die mehr als laienhaften Massnahmen unberufener Organe ganz empfindlichen Schaden genommen. Wir in Bamberg wissen nur zu gut, woher in den Bayreuther Beständen - soweit es sich namentlich um Akten-

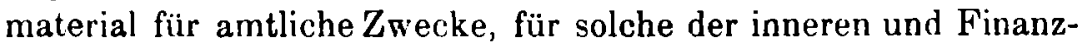
verwaltung u.s.w. handelt - gar manche klaffende Lücke stammt. 
Die unbestreitbaren hohen Verdienste schmälern zu wollen, welche Oesterreicher auch um diese: Archiv sich erworben hat, wäre vermessen und undankbar. Lnd doch wird kaum Jemand dem gewiss vortrefflichen Archivar und Gelehrten beipflichten können, wenn er in amtlichen, während des Umzugs erstatteten Berichten, wie z. B. in jenen vom 9. Februar 1814, 26. Nezember 1816, 12. Uezember 1817 sich folgendermassen äussert: „Nach den in meiner Anleitung zur Archivswissenschaft aufge:tellten richtigen (!) Grundsätzen gehören Akten ganz und gar nicht in ein Archiv", oder: ,Selbst die rein historischen Akten nahm ich nicht freiwillig, sondern nur auf Befehl des Ministeriums in das Archiv auf. Wäre in der reponierten Registratur Platz für sie, würde ich noch heute begutachten, dass sie dahin verbracht werden sollen“, oder: "Nur Urkunden sind in der Regel Gegenstand der Archive."

Sollten nun Grundsätze und Anschauungen, wie diese, in ihren Folgen nicht geradezu rerheerend gewirkt haben, manche tief zu beklagende Erscheinung nicht vollauf erklären und in keinerlei Beziehung zu den oben konstatierten, klaffenden Lücken im markgräflich Brandenburgischen Archive gebracht werden dürfen?!

Nach vorstehendem kurzen geschichtlichen Rückblick drängt sich wohl von selbst die Frage auf, wie die beiden in weiten Kreisen gelehrter Forscher besonders geschätzten Archive früher untergebracht waren und wie das Heim in allen seinen T'eilen beschaffen sein mag, das sie nunmehr gefunten haben.

Bis vor Kurzem konnten sie sich heineswegs einer Unterkunft erfreuen, die der Bedeutung ihrer Bestände für die wissenschaftliche Forschung, wie für die $\mathrm{Z}$ wecke der Verwaltung und Rechtspflege entsprechend gewesen wäre. Herbergten sie doch nur zum geringeren 'Teile in neun schönen, hellen und durchwegs trockenen Gelassen des Frdgeschosses unseres prächtigen Residenzschlosses, während die Hauptmasse in beklagenswerter Weise zusammengeschlichtet und aufeinandergehäuft in elf dumpfen, feuchten, teilweise unter dem Strassenniveau befindlichen und mit Modergeruch erfüllten Gewölben lagerte. Zudem erschien es röllig ausgeschlossen, nur einigermassen erheblichen weiteren Archivalien-Zugängen Raum zu gewähren, so dass z. B. an die Einverleibung der noch in Bayreuth bei der Re- 
gierung von Oberfranken verwahrten, recht dürftig geordneten und der wissenschaftlichen, wie amtlichen Ausnützung nur allzu lange entzogen gewesenen T'eile des alten markgräflichen Hofkammerarchivs nicht zu denken war.

Vor mehr denn 40 Jahren schon hatte man daher die Frage ernstlich in Erwägung gezogen, ob und inwieweit das erst zu Ende des 18. Jahrhunderts neu erbaute, zuletzt als Kaserne verwendete Karmelitenkloster Ersatz für die vom Archive belegten Räume des Residenzschlosses bieten möchte. Dieser Gedanke wurde im Jahre 1897, als die immer unhaltbarer gewordenen Zustände eine radikale Abhilfe dringend erheischten, wieder aufgegriffen und das $\mathrm{k}$. Kreisarchiv angewiesen, über die Brauchbarkeit, eventuell auch über den Kaufpreis des betreffenden Komplexes sich zu informieren und weiter zu untersuchen, ob die Klostergebäude auch zu passenden Arbeitszimmern, sowie zu Dienst wohnungen sich adaptieren liessen. Ich begab mich sofort nach dem hoch auf dem Kaulberge gelegenen Kloster, machte einen mehrere Stunden in Anspruch nehmenden Rundgang durch die weitläufigen Gebäulichkeiten, dabei den prächtigen, stimmungsvollen Kreuzgang mit seinen schlanken, romanischen Doppelsäulen und der reichen, allegorischen Skulptur der Kapitäle, das mächtige Bibliotheklokal, überhaupt jeden Saal und jedes Zimmer eingehend besichtigend. Das Ergebnis war die Konstatierung, dass ein zweckentsprechenderes und zugleich minder kostspieliges Gebäude - $65000 \mathscr{M}$. - für das oberfränkische Provinzialarchiv, zur Zeit wenigstens, kaum erworben werden könne.

Zwei Jahre waren seit diesen einleitenden Schritten noch nicht verflossen, als ein Erlass des $k$. Staatsministeriums des Innern an die $k$. Regierung von Oberfranken erging, dass zufolge Anregung des $k$. Allgemeinen Reichsarchives auf dem Komplex des vormaligen Kar:nelitenklesters an Stelle der abzubrechenden alten Gebäulichkeiten ein Neubau für das Bamberger Kreisarchiv, und zwar ein Beständehaus und ein hievon getrenntes Verwaltungsgebäude nebst Amtswohnung für den Vorstand und den Archivdiener in Aussicht genommen sei. Sofort wies die k. Regierung das hiesige Landbauamt an, im steten Benehmen mit dem Kreisarchive für den geplanten Neubau ein Projekt auszuarbeiten, in welchem die gegebene 
Situation, die Raumbedürfnisse und die neueren Erfahrungen über möglichst zweckmässige Anlage von Archiven entsprechende Berücksichtigung zu finden haben.

Wenige 'Tage nach dieser hocherfreulichen amtlichen $\mathrm{Kund}$ gebung unterbreitete ich der technischen Behörde sowohl als dem k. Allgemeinen Reichsarchive ein vom archiralischen Standpunkte aus entworfenes Programm, Norin icl: vor allem die wichtigste und nächstliegende Frage, ob bei dem projektierten Neubau das sogenannte Kabinetten-oder das Magazinsystem zur Anwendung gelangen solle, der eingehendsten Würdigung unterzog, sodann über die erforderlichen Räume, in specie iuber die Zahl und Grösse der in zwei lieschosse des Beständehauses einzubauenden Säle wie der im Verwaltungsgebäude unterzubringenden Bureaulokalititen mit Amtsbibliothek und Benützerzimmer etc. etr. und schliesslich über die mir zur Beantwortung vorgelegte Frage: ,Welche Mehrung unsere Archivbestände nach menschlicher Berechnung in etwa 100 Jahren erfahren möchten", in tunlichst erschiopfender Weise mich verbreitete. Der leider allzu früh verstorbene damalige Referent an k. Landbauamte Bamberg, Freiherr von Harsdorf-Enderndorf', brachte hierauf - am 30. September 1899 ein mit seltener Liebe und Sorgfalt, mit ungewöhnlichem Verständnis „auf Grund der, wie er berichtete, vom Archivvorstande erbetenen allgemeinen Gesichtspunkte und wiederholter persönlicher Rücksprachen und Beratungen mit demselben" ausgearbeitetes Projekt nebst Kostenanschlag bei hoher Stelle in Vorlage, und schon im März des Jahres 1900 ist seitens der k. Staatsregierung ein Nachtragspostulat zum Entwurf des Finanzgesetzes für die XXV. Finanzperiode in der Höhe von 560000 Wh. den versammelten Kammern des Landtags zugegangen.

Da trat noch kurz vor Schluss des Landtags nach siebenmonatlichem Zuwarten der Stadtmagistrat Bamberg auf den Plan und kam bei höchster Stelle mit dem wohl motivierten Antrage ein, es möge der Stadt der im Besitze des Finanzärars befindliche Komplex des alten Karmelitenklosters tauschweise gegen eine an der verlängerten Hainstrasse gelegene städtische Baugrundfläche überlassen werden. Die äusserst dringende, durch jede Verzögerung schwer gefährdete Angelegenheit des 
Neubaues, welche bereits nach allen Richtungen hin vollständig geklärt gewesen, nahm infolge dieses Angebotes sofort eine überraschende Wendung, und zwar, was die Lage des Gebäudes betrifft, nicht zum Schaden des wertrollen Provinzialarchives.

Nach genauer Untersuchung des Bauterrains und der (irundwasserverhältnisse - ich allein hatte mir von wissenschaftlicher wie technischer Seite drei Gutachten erbeten und nachdem die Frage, ob wegen der nahegelegenen, weitausgedehnten Hainanlagen die Baustelle in aussergewöhnlichem $M$ as s e dem Einflusse starker Nebel ausgesetzt sei und ob diese Nebel auch durch Fenster- und Schrankverschlüsse von empfindlichen Archivalien nicht genügend ferngehalten werden können, eine Lösung in günstigern Sinne gefunden, wurde ungesäumt an die Ausarbeitung eines neuen Projektes, das im allgemeinen a u dem Bauprogramm vom 30. September 1899 fusst und ebenso wie dieses mit einem unüberschreitbaren Kredit von $548000 \mathscr{M}$ zu rechnen hatte, gegangen und nach Genehmigung desselben seitens der berufenen Instanzen im Spätsounmer 1902 mit dem Bau begonnen.

Nun möge mir vor Allem gestattet sein, dass ich in rein sachlicher, vorurteilsloser Weise die Gründe zu entwickeln suche, die mich bestimmten, in meinem bereits oben erwähnten Bauprogramm von 1899 und wiederholt in späteren Berichten für die Wahl des Kabinettensystems, das nach dem Urteile eines hervorragenden Gelehrten und hochverdienten Leiters eines der grössten und wichtigsten Archive Europas, des Hofrats und Direktors des k. und k. Wiener Haus-, Hof- und Staatsarchives Dr. Winter, hier in Bamberg geradezu glanzvoll durchgeführt ist, mit aller Entschiedenheit einzutreten.

Der besonders ausserhalb meines engeren Vaterlandes weit verbreitete Glaube an das Dogma von der alleinigen Zweckmässigkeit des jede andere Richtung sieghaft niederringenden Magazinsystems für sämtliche Archivbauten ohne Ausnahme ist, man möge mir verzeihen, noch immer nicht allzu lebendig in mir. Bei Errichtung einer Schatzkammer der Geschichtswissenschaft, bei dem Neubau eines Archives mit seinem Reichtum an unersetzlichen Urkunden, Amtsbüchern und Handschriften als erstrebenswertestes Ziel einzig und allein weitgehendste Ausnützung des gegebenen 
Raumes gelten zu lassen, kann eine werbende Kraft für mich keineswegs haben. Und nur die Möglichkeit intensirster Verwertung jedes rorhandenen Raumteilchens und die dadurch bedingte relativ geringere Kostspieligkeit und grössere Einfachheit der Bauführung vermag, wie ich annehmen zu dürfen glaube, in erster Linie die dominierende Stellung z.1 erklären, welche das Magazinsystem seit geraumer Zeit auch bei Archivneubauten sich errungen hat.

Unbeding te Feuersicherheit, dies weitere stolze Attribut beregten Systems, es mag dagegen nimmer unbestrittene Geltung haben, es darf skrupellos und ohne Gewissensnot negiert werden; denn jedwede Gefahr durch Feuer kann doch da nicht $1 \mathrm{nb}$ bdingt - und bei diesem Worte setze ich ein - ausgeschlossen sein, wo, (in den „nur aus Stein und Eisen " hestehenden Magazinen nämlich) mächtige, durch vier und sechs Geschosse reichende Doppelgerüste, Regale und Kulissen, zahlreirhe Urkundenschränke von zum Teil ganz ausserordentlicher Grösse samt und sonders a us Holz gefertigt sind, also brembare Stoffe gewiss in Hülle und Fülle sich finden, ausserdem, wie in Weimar, ein Dachraum vorhanden ist, der mit einem Dache auf' hölzernem Einbau abgedeckt erscheint.

Und was will in einem nach dem Kabinettensystem errichteten, ganz abseits rom Verwaltungs- und Wohngebäude liegenden, nicht geheizten, nicht beleuchteten Archive, bei welchem alle im Laufe der Zeit gewomenen Ertahrungen verwertet sind, eine feuersichere Konstruktion der Treppen und Decken durchgeführt ist, unter dem Dache ein Gipsestrich liegt u.s. w., was will da, frage ich, in den einzelnen Kabinetten wohl anderes brennen, als eben auch nur die Aktengerüste und Urkundenschränke? Kann weiter, wenn es wirklich sich fügen sollte, dass über ein Archiv unseligerweise eine Brandkatastrophe hereinbricht, in einem Gebäude nach dem Kabinett:ystem, besonders wenn die Wasserleitung in alle Teile des Hauses bis unter das Dach geführt ist, das verheerende Element nicht auf einzelne Räume beschränkt bleiben? während in einem Magazine ernstliche Gefahr besteht, dass die einzelnen Pfeiler und Stützen, wenn sie einmal warm geworden, Ausbiegungen erleiden, und das ganze nur durch eiserne, durchbrochene Roste in beliebig viele Stockwerke geteilte, einen einzigen, gewaltigen Raum 
darstellende Archiv rettungslos in sich zusammenstürzt und die Katastrophe eine allgemeine wird. Und dann möge nicht rergessen werden, dass die Rauchentwicklung allein jeden Versuch, in dem mächtigen Raum vorzudringen und helfend und rettend einzugreifen, leider illusorisch erscheinen lässt.

Keinen geringeren, als jenen hochgestellten preussischen Architekten, nach dessen Plänen erst vor kurzem (1903) der vielfach als vorzüglich anerkannte Neubau des Düsseldorfer Staatsarchivs errichtet worden ist, darf ich hier als geradezu klassischen Zeugen dafür benennen, dass ich mich wahrlich nicht von unlauteren Motiven, wie eigen williger Liebhaberei, nörgelndem Widerspruchsgeist etc. etc., oder von rückständiger Anschauung und Gewöhnung leiten liess, als ich meinen obigen Befürchtungen bezüglich der durchbrochenen Roste etc. Ausdruck geben zu sollen glaubte. Bei einer in Düsseldorf während des 3. Deutschen Archivtages auf allgemeinen Wunsch eröffneten Diskussion über die Frage, ob durchbrochene Roste oder massive Decken den Vorzug verdienen, gab nämlich der k. pr. Baurat Bongard die schwerwiegende Erklärung ab, dass erstere nicht nur teuerer, als massive Decken sind, sondern dass

bei Brandunglück durchbrochene Roste die Verbreitung des Feuers geradezu befördern!

Nun, hab' ich denn oben etwas anderes behauptet? Man wird diesem Standpunkte gegenüber im Eruste kaum den Einwand erheben wollen, dass der Begriff "Magazinsystem“ ja gar nicht bedingt erscheint durch die Art und Weise, wie der zur Aufnahme des Archivmaterials bestimmte Raum in beliebig viele Etagen abgeteilt wird.

Durchbrochene Roste allein erachte ich und mit mir wohl viele Berufsgenossen, wie Techniker als das W esentliche, Charakteristische, wirklich Typische beregten Systems, und wenn an Stelle der Roste eingezogene massive Decken treten, kann nur zu Unrecht von der Anwendung des $r$ einen Magazinsystems gesprochen werden, hier ist das Wort: „Gemischtes System", dem schliesslich noch die Zukunft gehört, am Platze.

Und was trennt nun dieses letztere von jenem Saalsystem, wie es der Neubau des k. Kreisarchives Bamberg ausweist? 
Die unterscheidenden Merkmale sind im Grunde lediglich ein paar $\mathrm{Zwischenmauern!}$

Nunmehr darf ich rielleicht den Boden einer aus ganz allgemeinen Erwäımunen resultierenden Begrïndung meines Standpunktes in der Systemfrage verlassen und mir gestatten, in Kürze nachzuwejsoll. dass bei dem zweiten, wirklich zur Ausführung gekommenen Bamberger Neubauprojekt (Hainstrasse) noch Gründe ganz besonderer Art rorlagen, die mich veranlassten, der Anwendung des Kabinetten-besser Saal-Systems in der eindringlichsten Weise das Wort zu reden.

Wie ich schon einmal bemerken zu sollen glaubte, kann ich an die Selbstrerständlichkeit der Wahl des Magazinsystems in allen Fälle n von Archiv-Neubauten nicht recht glauben. Liegen doch die von bestimmendem Einfluss auf die Entstehung und ganze Entwicklung eines Projektes sich erweisenden, Ziel und Richtung gebenden Verhältnisse nicht i mmer und überall gleich. In unserem Falle z. B. hätte die K. Staatsregierung, wäre das Dogma von der ausschliesslichen Berechtigung des Magazinsystems durchgedrungen, auf die Erwerbung des schönsten in der ganzen Stadt Bamberg sich findenden Bauplatzes verzichten müssen. Niemals würde es nümlich, wie ich auf sofort eingezogene Erkundigung von autoritativster Seite erfahren habe, der Stadtgemeinde Bamberg eingefallen sein, zu gestatten, dass in der verlängerten Hainstrasse, die bei der vorgeschriebenen offenen Bauweise nur villenartige, aus Erd-und Obergeschoss bestehende Gebäude mit schön ausgestatteten Fassaden und freundlichen Vorgärten kennt, ein mindestens sechs bis acht Stockwerk hohes Magazin aufgeführt werde, - ein Bau also, der ${ }_{n}$ als mächtiger Kasten sich nicht für die Strassenfront eignet" und von dem, ich weiss nicht, ob mit Recht. ein hochverdienter Archivmann, ein alter begeisterter Vorkämpfer für das Magaz in, sagt:

"Wer nicht in der Lage ist, der Fassade eine untergeordnete Stellung anzuweisen, wird bei Anwendung des Magazinsystems wohl kaum mit der Möglichkeit, Einheit der inneren Eiurichtung zu erzielen, rechnen dürfen" ${ }^{1}{ }^{1}$ )

1) Burkhardt C. A. H.: „Das noue Archivgebäude in Weimar; Archivalische Zeitschrift. Bd. 11. S. $190 \mathrm{ff}$. 
Soll denn bei Archiv-Neubauten allein der von Architekten wie Lunsthistorikern anerkannte Satz, dass bei Ausgestaltung und Lösung von Bauaufgaben auch der Lingebung Rechnung zu tragen ist, seine (ieltung ganz und gar verloren haben? Die Beziehungen $z w i s c h e n$ Architektur und Landschaft sind ja in den letzten Jahren in Fachkreisen sowohl, wie in der Allgemeinheit immer mebr Gegenstand eingehender Erörterungen gewesen und in einer Entschliessung des Königl. Bayer. Staatsministeriuns des Innern vom 14. Juli 1905 wird geradezu gefordert. „auf die natürliche Beschaffenheit des Geländes und der umgebenden Landschaft, auf Wasserläufe, Baumbestände (wie hier der Hain) etc. etc. zu achten".

Das K. Preussische Hausarchiv ist bekanntlich in den letzten Jahren ebenfalls mit einem prächtigen, umfangreichen Neubau auf einem der schönsten Plätze Charlottenburgs bedacht worden. Für welches System nun glauhte das k. Hausministerium sich entscheiden zu sollen? Für das Kabinetten-System! Und welche Erwägungen waren ausschlaggebend für diese Wahl? „Die für die alten, hohen Räume des Berliner Schlosses, der früheren Heimstätte des Archive's, berechneten vier Meter hohen, schönen und kostspieligen Aktenschränke und Büchergestelle sollten nach der Meinung der Architekten selbstvetständlich im neuen Gebäude wieder untergebracht werden, und es war damit von vornherein entschieden, dass nicht das jetzt übliche, allerdings praktische, aber weniger schöne sogenannte Magazinsystem durchgeführt werden konnte, sondern den Möbeln entsprechend stattlich hohe Archivsäle (Kabinettensystem) hergestellt werden mussten, welche freilich an nichts weniger als an Aktenspeicher (Magazine) erinnern. ${ }^{11}$ )

Wenn nun in Charlottenburg Möbel- und Aktenschränke den Archivneubau in entscheidender Weise beeinflusst haben, durfte da in Bamberg für die Wahl des Systems nicht ein Bauplatz mitbestimmend sein, der in einem Villenviertel gelegen ist, wie ein schöneres wohl keine Stadt des Frankenlandes aufzuweisen hat, das durch ortspolizeiliche Vorschriften vom Jahre 1896 vor jeder Russ- und Rauchbelästigung, vor jeder von aussen

1) Grossmann J., das K. P. Hausarchiv zu Charlottenburg. Arohival. Zeitschrift, Neue Folge, Bd. VI. S. $280 \mathrm{ff}$. 
drohenden Feuersgefahr in wirksamster Weise dadurch geschützt erscheint, dass in der ganzen Lmgebung des Haines die Frrichtung und der Betrieb einer Anlage im Sinne des $\S 16$ der Gewerbeordnung, sowie sonstiger, Lärm u. s. w. verursachender Anlagen, ja selbst die Führung einer Bäckerei ausgeschlossen ist?

Durfte wirklich eine derartige Baustelle, die mit ihrer mächtigen Schicht reinen, scharfrissigen Sandes, mit ihrer nach allen Seiten hin freien Lage einen Baugrund von ganz ausserordentlicher, für hiesige Verhältnisse geradezu ungewöihnlicher Trockenheit bietet, eines Systems wegen, das sich noch lange nicht, in ununterbrochenem Siegeszuge die Welt erobert hat", geopfert werden? Nicht ein Tropfen Wasser ist gelegentlich des von mir Tag für Tag genau beobachteten Erdaushubes an irgend einer Stelle des etwa $6900 \mathrm{qm}$ grossen, also volle zwei Tagwerke umfassenden Platzes trotz tiefer Fundierung, und obwohl der Grundwasserstand zu jener Zeit ein sehr hoher gewesen, zum Vorschein gekommen.

Ziehen wir übrigens die Bauplatzangelegenheit und ihre Vorgeschichte hier nicht weiter in Würdigung; es meint ja ohnehin kaum jemand, dass man sich in Bamberg und besonders an der allein massgebenden Stelle in München nur tür enge vier Wände begeistern zu sollen glaubte:

Hohe luftige, zum Teil gegen 200 ym grosse Säle mit einem durch zahlreiche hohe und dabei breite Fenster bedingten mächtigen Lichteinfall;

eine möglichst intensi re Ra umausnützung, welche dadurch erzielt worden ist, dass sämtliche, von zwei Seiten belichtete Regale immer senkrecht zur Fensterachse, bezw. zum Pfeilermittel zu stehen kamen;

drei Granit- und Hausteintreppen, welche alle Teile des gewaltigen Hauptbaues in der zweckmässigsten Weise untereinander verbinden, den Verkehr in sämtlichen Sälen und Gängen ungemein erleichtern und eine ebenso schöne als vorteilhafte Gliederung innerhalb der Geschosse bedingen; dazu nicht weniger als

vier hohe, breite Torausgänge, durch welche in der Stunde der Not und Gefahr leicht zu retten ist, was überhaupt gerettet werden kann: 
ist aus dieser in kurzen Strichen gegebenen allgemeinen Skizze vielleicht zu entnehmen, dass die herrlichen, ungemein stark benützten Bestände des Kreisarchives Bamberg verurteilt sind. eingezwängt in vier enge Wände* ein kümmerliches, lichtund luftarmes Dasein zu fristen? Man möge doch sehen, welch schönes Heim auch unser reicher, bestgeordneter Urkundenschatz im Neubau gefunden hat, wie nahezu 70000 Dokumente in 528, unten ausführlich $z u$ beschreibenden, massiv eichenen Schränken in gleichfalls hohen, luftigen, von den Aktensälen vollständig getrennten Räumen des Mitteltraktes lagern, dass wir also nicht veranlasst sind, Hunderte von Kästen in dell Gängen zwischen die Aktengestelle einzuschieben ${ }^{1}$ ), oder Tausende von Pappkartons in offene Regale zu legen und so das Urkundenmaterial nach Umständen allem Staub und Schmutz, feuchter Luft elc. etc. auszusetzen. ${ }^{2}$ ) Vergessen wir insbesondere nicht, dass die Projektierung unseres Neubaues unter ängstlicher Berücksichtigungeinermöglichstgünstigen Aufstellung der Aktenregale und Urkundenschränke erfolgte, woraus eine bestinmte Abmessung der Fensterachsen und zwar verschieden je nach Räumen für Aktenregale und solchen für Urkundenschreine sich ergab.

Hier ist es vielleicht am Platze, zur Frage der Urkundenverwahrung im allgemeinen auch den ehemaligen Weimarer Archivdirektor Burkhardt, der, wie schon erwähnt, stets für das moderne Magazin eingetreten ist, zu hören:

"Das belgische, i. e. Magaziusystem schliesst, wenn man aus der Raumersparnis desselben nicht ausgiebigen Nutzen ziehen will, die Aufstellung von Urkundenschränken. an die sich unsere Archiv-Verwaltungen gebunden erachten, völlig a us." (?!)

Doch genug hievon, es kann ja nicht weiter meine Aufgabe sein, die einzelnen. Systeme rom archivalischen Standpunkte aus auf ihre besonderen Vorteile und Mängel zu prüfen; die Frage, welches wohl das relativ beste sein mag, ist ja für Bamberg längst nicht mehr aktuell; ich bin auch weit entfernt, ein abschliessendes Urteil mir anzumassen, oder gar den wirk-

1) Siehe Beilage zur Allgemeined Zeitung pro 1896, N. 216 S. 3.

2) Archival. Zeitschrift, Neue Folge Bd. VI. S. 29 ?. 
lichen, unleugbaren Vorzügen des Magazinsystems gegenüber mirh ablehnend zu verhalten, es drängt mich viehnehr, rückhaltslos zu erklären, man müsse in den Kreisen der Archivbeamtell der massgebenden Stelle nur aufrichtigsten Dank und ehrerbietige Anerkennung dafür zollen, dass auch in Bayern, speziell in der Rheinpfalz ein Versuch mit dem Magazinsystem gemacht worden ist; es muss ja Alles geprüft und das Best' behalten werden; ungemein töricht wäre es, ferner nicht vollauf würdigen zu wollen, dass in grossen Städten dir schier unerschwinglich hohen Kosten für Erwerb von Grund undBoden gebieterisch dazu drängen, stark in die Höhe gehende Magazine zu bauen. Ich vertrete ja nur - in der Defensivemich befindend - den gewiss bescheidenen Standpunkt, nicht jenen für rückständig zu erachten, der die ebenso ehrliche als unerschütterliche Ueberzeugung hegt, dass es auch Faille geben kann, in denen bei Archiv-Neubauten das - ich möchte sagen - modernisierte Saalsystem, wie es hier in $\mathrm{B}$ a mberg durchgeführt ist, ganz akzeptabel erscheint; ich bitte, nur anzuerkennen, dass selbst der vielumworbene heutige Aktenspeicher das Los allermenschlichen Einrichtungen und Schöpfungen: ,nicht frei von Unvollkommen heiten zu sein", teilen muss.

Unschwer lässt sich aus den Verhandlungen des dritten und vierten Deutschen Archivtages in Düsseldorf, bezw. Danzig 1903 und 1904 erweisen, dass die Techniker und Archivare noch immer nicht geschlossen für die alleinige Berechtigung des Magazinsbaues eintreten und dass auch ich in guter Gesellschaft mich befinde und bis zur Stunde kaum in eine gänzlich isolierte Lage geraten bin.

Den Erbauer der vielgerühmten Heimstätte des Iüsseldorfer Staatsarchives haben wir mit seiner vemichtenden Kritik des feuerbefördernden Rostsystems bereits gehört; Archivdirektor Wolfram-Metz sprach von den Vorteilen des gemischten Systems, während Geheimrat Doebner-Hannover das Ideal der Franzosen, i. e. die praktische Ausnülzung des Raumes durch Galleriebauten pries; Professor Thudichum-'Tübingen forderte zur Beseitigung der Feuersgefahr steinere Wölbungen; Archivrat Ilgen-Düsseldorf negierte die Notwendigkeit eines Normalbaues und Geheimrat Grotefend gab, nachdem er an den 
grossen Brand des Archivs in Schwerin, wobei nur 16 Faszikel verloren gingen, erinnert hatte, sein schwer ins Gewicht fallendes kompetentes Crteil wörtlich dahin ab:

"Das beste Sicherungsmittel gegen Feuer ist die Trennung von Archiv- und Arbeitsräumen; sonst möge ein Archivgebäude gebaut sein, wie es wolle, bei einem wirklich grossen Brande wird es ohne absperrende Gow ölbe, wie sie ein Magazinsbau nie und nimmer haben kann, verloren sein. ${ }^{1}$ )

Keinen Zweifel über seine stellungnahme zur Systemfrage liess endlich Archivdirektor Bär-Danzig, Vorstand des erst im Jahre 1900 neubegründeten Staatsarchivs für die Provinz Westpreussen aufkommen, der gelegentlich des vierten Deutschen Archivtages am 8. August 1904 über das Entstehen dieser jüngsten Anstalt, wie über den Bau, die innere Einrichtung und die Bestände derselben nähere Mitteilungen machte. Nachdem er zunächst festgestellt hatte, dass der Neubau aus einem Verwaltungsgebäude und zwei zur Aufnahme der Archivalien bestimmten Magazinen besteht und dass von letzteren ursprünglich nur eines gebaut werden sollte und ein zweites erst angefügt wurde, als man das gänzlich Unzureichende des einen Magazins noch rechtzeitig erkannt hatt $\theta$, liess er eine Charakteristik der Gebäude folgen, die ich hier wörtlich wiedergeben zu dürfen glaube:

"Die Archivhäuser sind in der jetzt bei uns in Preussen und anderswo üblichen Weise erbaut, unschöne niedrige Geschosse, die zwar - das einzige Gute an ihnen bequem in Reichhöhe die Akten aufbewahren lassen, ${ }^{2}$ ) die aber namentlich in den untersten Geschossen bei der Niedrigkeit der Fenster nicht so ausreichend belichtet werden können, wie es für die Akten nötig ist" ${ }^{3}$ )

So lauten die Urteile Deutscher Archivare aus der allerjüngsten Zeit.

In wirklich genialer Weise und mit bewunderungswürdigem technischen Geschick erscheint der im Jahre 1902 vollendete

1) Protokolle des dritten Deutschen Archivtags zu Düseeldorf. 1902 S. 48 und 49.

1) Ist bei jertem System möglich. Siehe Bamberg

3) Protobulle des vierten deutschen Archirtags zu Danzig. 1904. S. 45. 
Neubau des k. und k. Haus-, Hof- und Staatsarchivs in Wien durchgeführt. $Z$ u diesem Urteil wird wohl jeder unwillkürlich gelangen müssen, der einerseits das zur Verfügung gestandene äusserst beschränkte und ungünstig gelegene Bauterrain kennt und anderseits die unterzubringenden gewaltigen Massen des Riesenarchivs zu würdigen weiss.

Wenn nun der allverehrte Leiter dieser Musteranstalt in seinem auf dem sechsten Deutschen Archivtag am 24. September 1906 gehaltenen informatorischen Vortrag über das neue Archivgebäude mit Nachlruck hervorhob, dass ihm die Wahl zwischen Magazin- und Saal-System keinerlei Qual bereitet hat, so bin ich ohne $\mathrm{Z}$ audern der erste, welcher angesichts der Verhältnisse, wie sie in Wien nun einmal lagen, die zwingende, Notwendigkeit eines echten und rechten Magazinbaues von der Anlage und Beschaffenheit des am 24. September 1906 von uns besichtigten und bewunderten voll und ganz anerkenne.

Auch die weitere Erklärung des Hern Hofrats Dr. Winter, es wäre selbst in dem Fall, dass ein ungemessener Bauplatz zur Verfügung gestanden hälte, bezüglich des Systems ebenso, und nicht anders entschieden worden, möchte ich mehr als begreiflich finden; nur glaube ich, nicht allzuweit von dem Standpunkte des lierrn Archivdirektors selbst abzuirren wenn ich annehme, dass, wäre wirklich ein ungemessener und besser gelegener Bauplatz vorhanden gewesen, man trotz weitgehender Ausnützung des Magazinsystems vielleicht doch anders als geschehen ist, gehaut haben würde. Archiv-Verwaltung, wie Bauleitung sind unter dem Drucke von Verhältnissen gestanden mit denen einmal gerechnet werden musste und die eben stärker als die Menschen waren. Ier gewiss sachkundige Vorstand des weltbekannten Zentralarchivs, vor dessen Autorität ich mich gerne beuge, hat ja selbst gesagt:

"Vor Allem bitte ich, sich ror Augen zu halten, dass wir des Vorteils, dessen sich die neueren deutschen Archivbauten in so reichem Masse erfreuen konnten - der Möglichkeit breiter Auseinanderlegung des Baues nämlich — entbehren mussten."

Und doch ist und bleibt das Wiener neue Archivgebäude ein Meisterstück moderner Technik, das seinem Schöpfer für 
alle Zeiten einen Ehrenplatz in der Baugeschichte der alten schönen Kaiserstadt sichern wird.

Nunmehr glaube ich mit der ohnehin schon allzubreit verlaufenen Besprechung der Systemfrage, welche bei Archivneubauten stets von aktuellster Bedeutung, von ganz besonderer Wichtigkeit sich erweisen wird, abschliessen und zur näheren Beschreibung des Bamberger Monumentalbaues selbst übergehen zu sollen.

\section{Die Gebäudegruppe}

des königlichen Kreisarchives liegt in der verlängerten Hainstrasse, Ecke der neuhergestellten Sodenstasse. Der Idealwunsch jeder Archiv-Verwaltung, einen $n$ ach allen Seiten freien Baugrund zu gewinnen, ist bei uns Dank dem grossen Entgegenkommen der Stadtgemeinde Bamberg verwirklichet worden. Der Bauplatz liegt, wio schon oben erwähnt, in einem scharf abgegrenzten Villenviertel, das durch ortspolizeiliche Vorschriften vor jeder Russ- und Rauchbelästigung, vor jeder von aussen drohenden Feuersgefahr in wirksamster Weise geschützt erscheint. Mit ihrer mächtigen Schicht reinen, scharfrissigen Sandes ist die Baustelle von ganz ausserordentlicher, für hiesige Verhältnisse geradezu ungewöhnlicher Trockønheit und der Grundwasserspiegel, der von der Stauhöhe des benachbarten, den Hain nördlich begrenzeuden Wasserlaufes, des sogenannten Hollergrabens, zeitweise abhängig ist, liegt im umgünstigsten Falle immer noch $60 \mathrm{~cm}$ unter Kellerfussboden-Oberkante. Besonders nach Vollendung des grossen städtischen Kanalisationswerkes gilt, wie ich aus einem von mir erbetenen Gutachten des K. Strassen- und Flussbauamtes ersehe, ein Aufstall des Grundwasserspiegels, der dem weitläufigen, in Zementmörtelmauerwerk (Beton) ausgeführten Kellergeschoss gefährlich werden könnte, als vollständig ausgeschlossen.

Die Stadtgemeinde Bamberg vertauschte laut notariellen Vertrags vom 15. Juli 1902 diesen Bauplatz - eine an der Hainstasse gelegene Wiese zu 0,682 ha oder zwei Tagwerk -in lastenfreiem Zustand an das K. Statsärar gegen dessen auf dem Kaulberge befindliches, 0,603 ha oder ein Tagwerk siebenundsiebzig Dezimale grosses Anwesen, bestehend in dem säkularisierten, mit dem Fürstentum Bamberg im Jahre 1803 an die 
Krone Bayern ühergegangenen Karmelitenkloster nebst Kirche. Der Wertsanschlar des Bauplatzes hat sich ebenso wie jener des staatlichen Anwer.ns auf su000 Mark berechnet, so dass kein T'eil an den anderen eine Tauschaufgabe hinauszubezahlen brauchte.

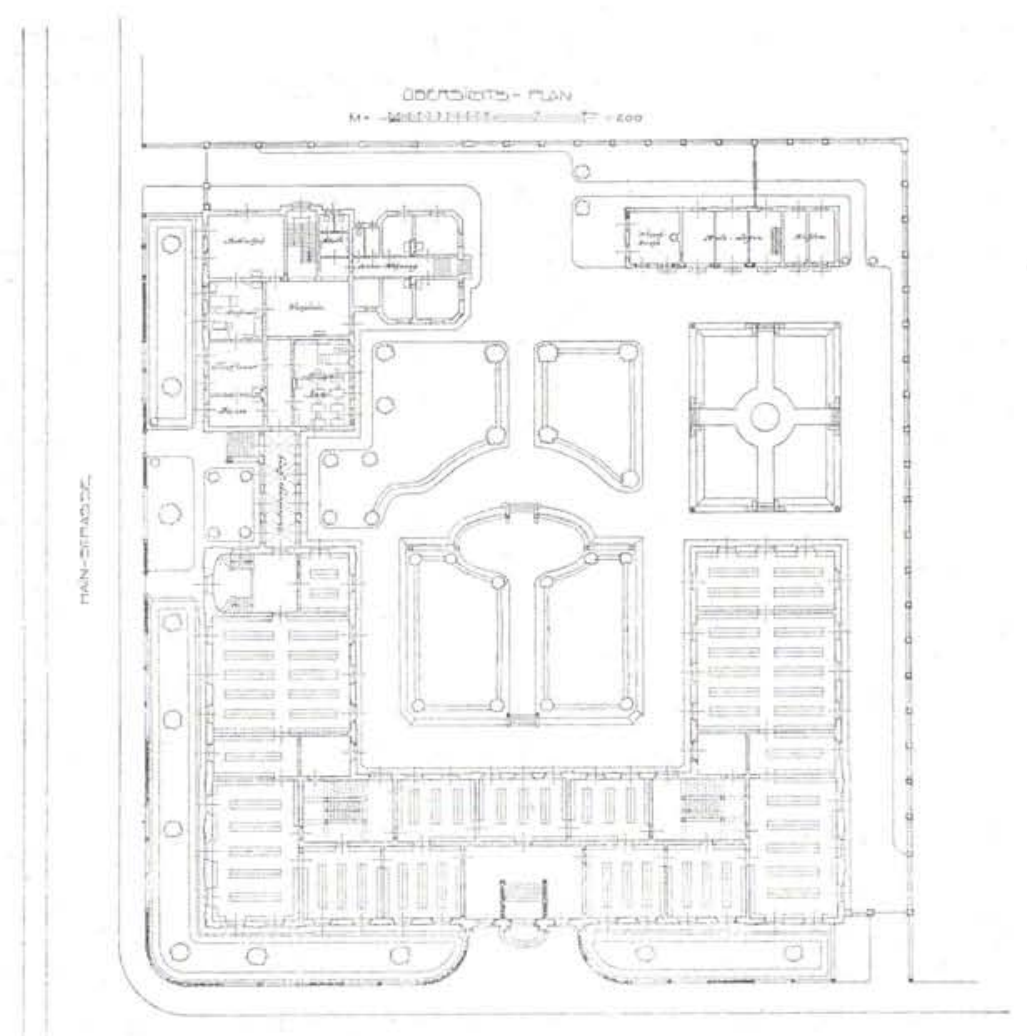

Abbildung 1. Uebersichtsplan der ganzen Archisanlage.

Vertragsgemäss übernahm das K. Staatsärar u. a.

1. die Auffüllung des ganzen Areals, soweit dasselbe nicht überbaut worden ist, auf Höhe der Strassenplanie;

2. die Herstellung und Auffüllung eines Trottoirs aus Asphalt an der Sodenstrasse und der verlängerten Hainstrasse auf Anwesenslinge;

3. den halben Anteil der Kosten für Anlegung der Sodenstrasse auf Anwesenslänge bzw. auf $78,4 \mathrm{~m}$; 
4. die Herstellung der notwendigen Umfriedungen in den beiden mehrgenannten Strassen;

j. die Verpflichtung, die Flächen zwischen den Einfriedigungen und den Gebäuden als Vorgärten anzulegen und zu unterhalten.

Die Stadtgemeinde dagegen war gehalten, zum $\mathrm{Z}_{\text {wecke }}$ entsprechender Ableitung der gegen die Strassen sich ergebenden Meteorwässer eine Rinnenpflasterung und an geeigneten Stellen Einfallschächte anzubringen, desgleichen nach Fertigstellung der Archivgebäude die äussere Hain- und Sodenstrasse entsprechend zu beleuchten, sowie die Gas- und Wasserleitung,

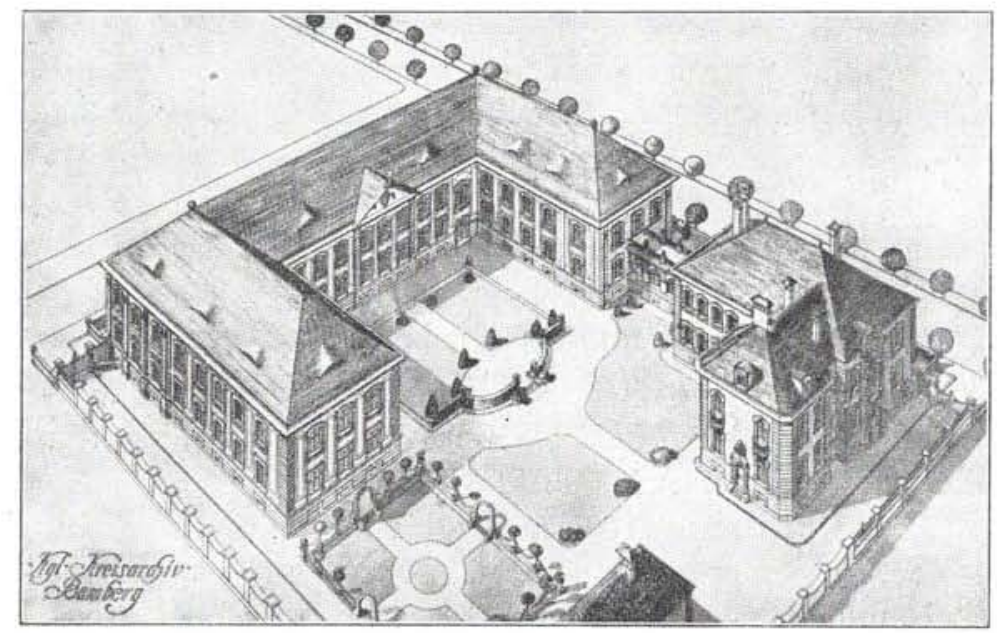

Abbildung 2. Die Archivanlage aus der Vogelschau.

in Falle eines Bedürfnisses auch die elektrische Leitung zum Zwecke des eventuellen Anschlusses der Archivgebäude an das städtische Elektrizitätswerk bis in die Sodenstrasse fortzuführen. Endlich verzichtete die Stadtgemeinde dem K. Aerar gegenüber auf jedweden Kostenersatz für bessere Instandsetzung der Hainstrasse.

Von besonderer Wichtigkeit erscheint sodann die im Vertrage festgelegte Bestimmung, dass der in $\$ 6$ Abs. 2 der ortspolizeilichen Vorschriften vom 25. August 1896 für Neubauten der Angrenzer normierte Abstand von der Nachbargrenze auch dann einzuhalten ist, wenn bei dem Archivneubau die Entfernung 
von der Nachbargrenze mehr als $5 \mathrm{~m}$ betragen sollte (was natürlich der Fall ist). Das Recht des Staatsärars auf strikte Einhaltung dieses Abstandes musste nicht nur auf den Bauplatz selbst, sondern auch auf den beiden an denselben auf der Nord west-, wie Südostseite anstossenden Grundstücke als Grunddienstbarkeit zugunsten der Archirgebäude im Hypothekenbuche eingtragen werden.

Die ganze Südwestseite - die dem Neubau entgegengesetzte Seite der Hainstrasse - kann gemäss Ortsstatut von Jahre 1896 mit Rücksicht auf den Hain und die demselben vorgelagerten Wiesengründe, bezw. Anlagen überhaupt nie bebaut werden und gegen Süden (Mitlelbau des Beständehauses mit einer nahezu $70 \mathrm{~m}$ betragenden Frontlänge) bleibt das Archiv durch die Vorgärten, die Sodenstrasse und die Trottoirs derselben bei allenfallsigen Neubauten mehr als $25 \mathrm{~m}$ von dem Nachbargrundstücke entfernt.

Ein Bauplatz nun, so bevorzugt durch seine Lage und so begünstigt durch staatliche wie gemeindliche Fürsorge, wird wohl den einen oder anderen Vorteil eines Magazingebäudes, das übrigens einem Villenviertel von der prächtigen Ausgestaltung des hiesigen nicht im mindesten angemessen und auch, um dies wiederholt zu konstatieren, gar nicht zugelassen worden wäre, vollständig aufwiegen.

Die Fundamente des Archivneubaues ruhen in einer Tiefe von 5,10 Meter, gerechnet ab Oberkante des Muschelkalksockels, und in einer Breite von $1,30 \mathrm{~m}$ in ungemein trockenem, aus grobkörnigem Sande bestehendem Boden.

Die Grund- und aufgehenden Mauern der Umfassungen wurden bis Muschelkalksockel - Unterkante, Côte - 45 in Kiesund Schotter-Beton aufgeführt, die Grundmauern der Zwischenwände desgleichen, aber um $30 \mathrm{~cm}$ über Kellerfussboden.

Eine Isolierschichte von Asphaltfizlplatten mit Bleieinlage zur Abhaltung der aufsteigenden Bodenfeuchtigkeit liegt in der Höhe - 45 über sämtliche Mauern.

Von der Côte $-45 \mathrm{ab}=$ äussere Bodenhöhe, beginnt das sichtbare Mauerwerk mit einer Höhe $11,30 \mathrm{~m}=$ Côte $+10,85$ am Beständehaus und 10,15 am Verwaltungsgehäude. Die Umfassungsmauern an den Strassenseiten sind durchwegs in Haustein ausgeführt und die Stossfugen mit reinem 
Zementmörtel ausgegossen. An den Hofseiten wurden nur die Sockel-, Lisenen-, Tür- und Fensterumrahmungen in Haustein behandelt und so ein wirkungsvoller Gegensatz zu den weiss verputzten Mauerflächen geschaffen.

Das Hausteinmaterial, welches die Sandsteinbrüche in Medlitz und Birkach lieferten, gilt als das beste der Bamberger Umgebung. Das Korn hat mittlere gleichmässige Grösse von durchwegs warmer einheitlicher Farbe und zeichnet sich durch hervorragende Wetterbeständigkeit und Wasserundurchlässigkeit aus; es verträgt jede Profilierung und Behandlung, gibt scharfe Kanten und erscheint für jede Ausführung von Bildhauerrabeiten besonders geeignet.

Ein Muschelkalksockel von $50 \mathrm{~cm}$ Höhe und darauffolgend ein Sandsteinbrüstnngsmauerwerk von $2,00 \mathrm{~m}$ Höhe umläuft den ganzen Bau.

Die Kotierung desselben ergibt für

A das Beständehaus:

Kellerfussbodenoberkante: $-2,55$

Erdgeschossfussbodenoberkante : $+1,05$

Obergeschossfussbodenoberkante: $+5,55$

Dachgeschossfussbodenoberkante: $+10,05$

Oberkante Hauptgleiche: $+10,85$

Firsthöhe: $+18,35$,

B für das Verwaltungsgebäude

Kellerfussbodenoberkante: $-2,55$

Erdgeschossfussbodenoberkante: $+1,05$

Obergeschossfussbodenoberkante: $+5,55$

Dachgeschossfussbodenoberkante: $+9,55$

Oberkante Hauptgesims: $+10,15$

Firsthöhe: $+17,20$

Die lichten Geschosshöhen im Beständehaus betragen bei einer Deckenkonstruktionshöhe von durchschnittlich $26 \mathrm{~cm}$ $4,24 \mathrm{~m}$

und im Verwaltungsgebäude:

4,24 $\mathrm{m}$ im Erdgeschoss mit den Amtslokalitäten und

3,98 $\mathrm{m}$ im Obergeschosse mit der Dienstwohnung des Kreisarchiv-Vorstandes. 
Sämtliche Gebäude wurden unterkellert mit Ausnahme des die Waschküche, Holzlegen und Kohlenräume enthaltenden Nebengebäudes.

Das Kellergeschoss ist ron dem Erdgeschosse im Beständehaus und Verwaltungsgebäude durch Tonnengew ölbe, bezw. Krouzge wöl be, die auf Sandsteinpfeiler gestützt sind. getrennt; für alle anderen Decken wurde die gerade zwischen eisernen T-Trägern verlegte "Deutsche $\mathrm{Wabensteinmassivd \theta cke}$, die wegen ihrer geringeren hygroskopischen Eigenschaften den Vorzug vor der Betondecke verdient und bei welcher die Untersicht mit Kalkmörtel glatt verputzt ist, die Unterzüge dagegen mit Rabitzummantelung und Hohlkehlen versehen sind, gewähit.

Bezüglich des Fussbodenbelags kommt kurz zu berichten, dass im Kellergeschoss ein solcher von Beton genügt, während bei den übrigen Geschossen in allen Sälen, Zimmern, Dielen und Gängen ein olirgrüner linoleumbelag auf ca. $3 \mathrm{~cm}$ hoher Gipsestrichunterlage und Sandbettung vorhanden ist. In den Treppenhäusern, und Vestibülen, im Verbindungsgang und in den Nebenräumen, wie im Gang der Dienerwohnung finden sich Solnhofer und Mettlacher Platten angebracht.

Das Bauprogramm ergab folgende

Masseneinteilung:

1. das Beständehaus,

2. das Verwaltungsgebäude,

3. den Verbindungsgang,

4. das Nebengebäude,

5. den Hofraum mit Gartenanlagen,

6. die Vorgärten an den Strassenseiten.

Die üppige, reiche, Architektur der gesamten Bauanlagen zeigt die Bauformen des Bamberger Barockes, der hier besonders glänzend noch durch das am Fusse des Stefansberges gelegene sog. Prellhaus und das nicht weit davon befindliche Konkordiagebäudo vertreten ist. Beide Häuser liess Anfangs des 18. Jahrhunderts der von mir bereits oben rühmend hervorgehobene Bamberger Archivar und Hofrat Johann Ignaz Tobias Böttinger in einem der abgelegensten Stadtteile mit riesigen Kosten aufführen. Sie zählen unbestritten zu den interessantesten hiesigen 
Privatbauten und namentlich das Prellshaus „mit seinen prunkvoilen Ornamenten von schöner Zeichnung, scharf und kräftig herausgemeisselt, erzeugt einen derartig malerischen Effekt, dass man in seinem Zauber befangen nur an den lebens- und genussfrohen Luxus des 18. Jahrhunderts denken kann“.

Dieses von Gurlitt in seiner Geschichte des Barockstils und des Rokoko besonders gewürdigten Hauses darf schon des-

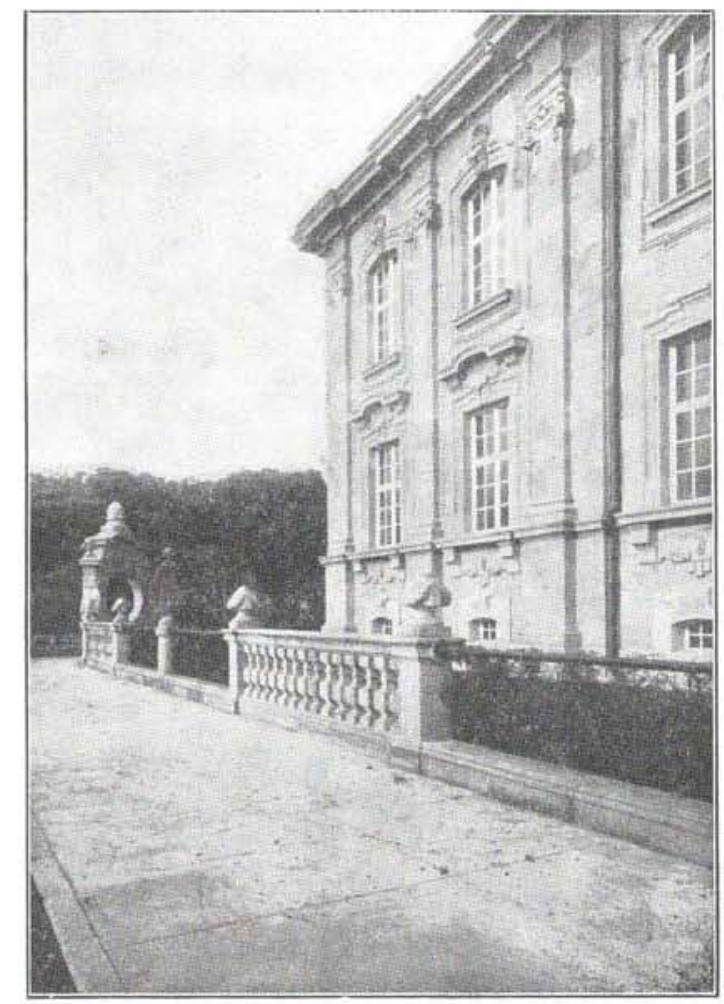

Abbildung 3. Gebäudeteil an der Ecke der Soden- und Hainstrasse.

wegen Erwähnung geschehen, weil es auch bei unserem Archivneubau eine Rolle und zwar genau dieselbe spielte, wie 20 Jahre früher das in Nürnberg auf der Höhe des Egidienberges 1605 im reinsten Stil deutscher Renaissance erbaute, so berühmte Pellerhaus bei der seinerzeitigen Errichtung einer neuen Heimstätte für das mittelfränkische Provinzialarchiv. Beide Objekte sollten vom Staate erworben und zu Archivgebäuden einge- 


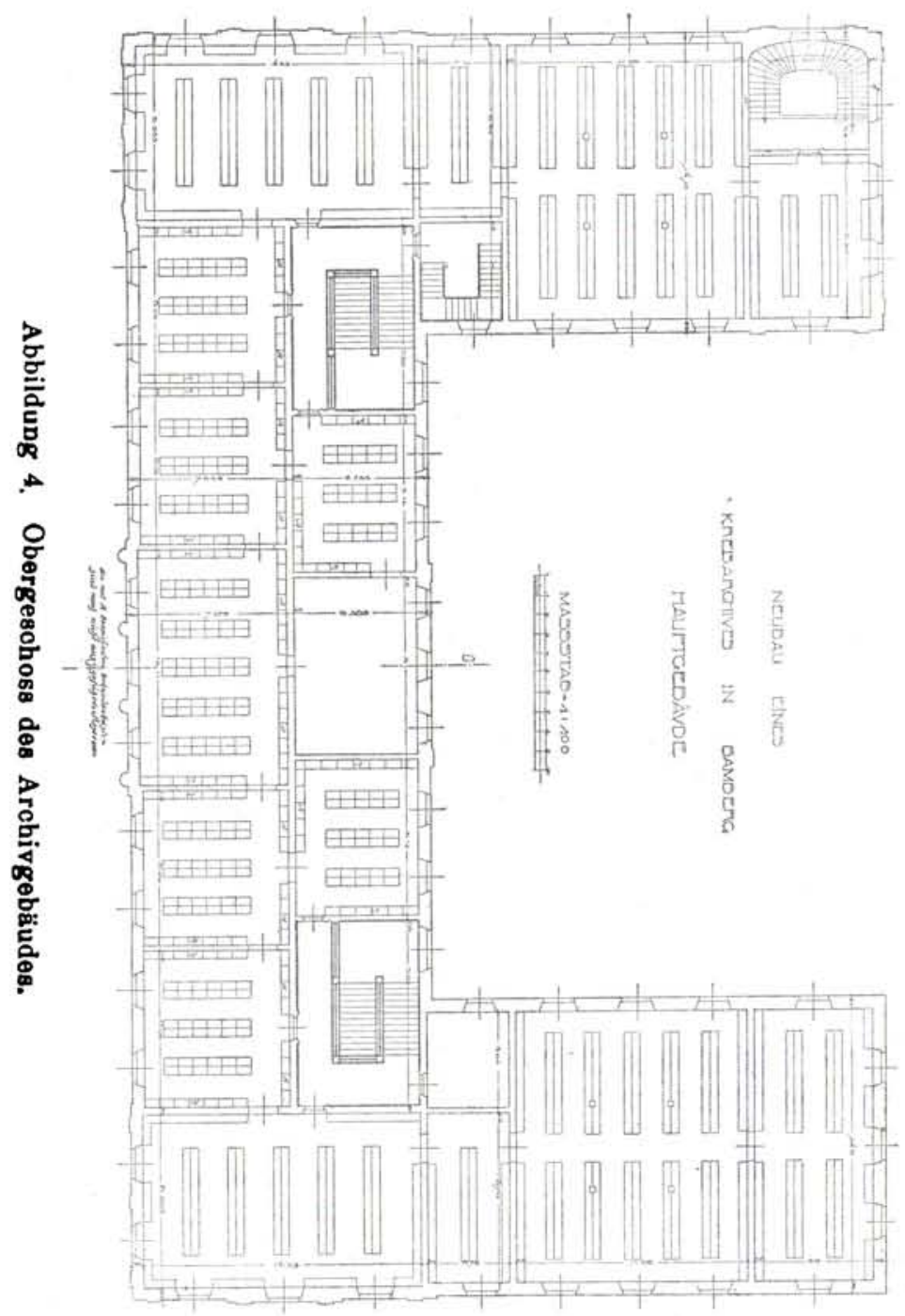


richtet werden. Zahllose Architekten und Kunsthistoriker hätten sich dann an den feinen und sinnreichen Schöpfungen und Motiven der genamnten alten Baustile belehren und erfreuen können.

Allein es gebrach bei näherem Zusehen in beiden Fällen am Allernötigsten - an Raum, an Licht und Luft und man hat deswegen, in Nürnberg wenigstens, „trüben Blickes von einer schönen Hoffnung Abschied nehmen müssen".

Hier in Bamberg, wo in archivalischen, wie technischen Kreisen das von einem einflussreichen, nicht mehr lebenden Mitgliede des Stadtregiments ausgegangene, eine kaum glaubliche Unkenntnis der Grösse des heimischen Archives verratende "Prellhausprojekt" gleich von Anfang an wenig ernst genommen wurde, ist "das Abschiednehmen " nicht besonders schwer gewesen. Gab ich doch sofort meiner Anschauung von der gänzlichen Unzulänglickeit des Gebäudes, das nicht den vierten Teil der Archivbestände fassen körnte, in der unzweideutigsten Weise Ausdruck und zwar schon vor der am 28. April 1899 auf meinen Antrag erfolgten kommissionellen Besichtigung des Hauses.

Die beiden allein in Betracht kommenden Obergeschosse hätten im ganzen nur ca. 450 qm nutzbare Bodenfläche zu bieten vermocht, das ist weniger als die Hälfte des im königlichen Residenzschlosse zur Verfügung gestandenen, seit Jahrzehnten schon als völlig unzureichend erkannten Raumes von $959 \mathrm{gm}$. Wie ganz anders liegen zum Heile des einzig schönen Bamberger Archives die Verhältnisse in dem mächtigen Neubau mit mehr als 2500 qm Gesamtbodenfläche der Säle!

Das zweigeschossige Hauptgebäude oder Beständehaus

setzt sich zusammen aus dem $66 \mathrm{~m}$ langen Mitteltrakt und aus $z$ wei Seitenflügeln mit je 23,5 m Länge; die Tiefe beträgt durchgehends $15,62 \mathrm{~m}$.

Die Fassade des Mittelbaues an der Sodenstrasse bildet der Grundrissanlage entsprechend die Hauptront des Beständehauses. In gleichmässiger Anordnung "zur.] Mittelachse entwickeln sich zwei dreiachsige, wenig vorspringende Eckri- 
salite mit Pilastergliederungen im Gegensatz zum kräftig vorstrebenden vierachsigen $\mathbf{M i t t e l}$ risalit mit ${ }^{3}{ }_{4}{ }_{4}$. Säulen, auf denen sich eine einfache, aber geschmack volle At tika mit vier Monumentalfiguren und dem grossen bayerischen Wappen erhebt. Von den Statuen, welche aus bestem Kelheimer Marmor gehauen sind und zu denen Professor Anton Hess mit den Bildhauern

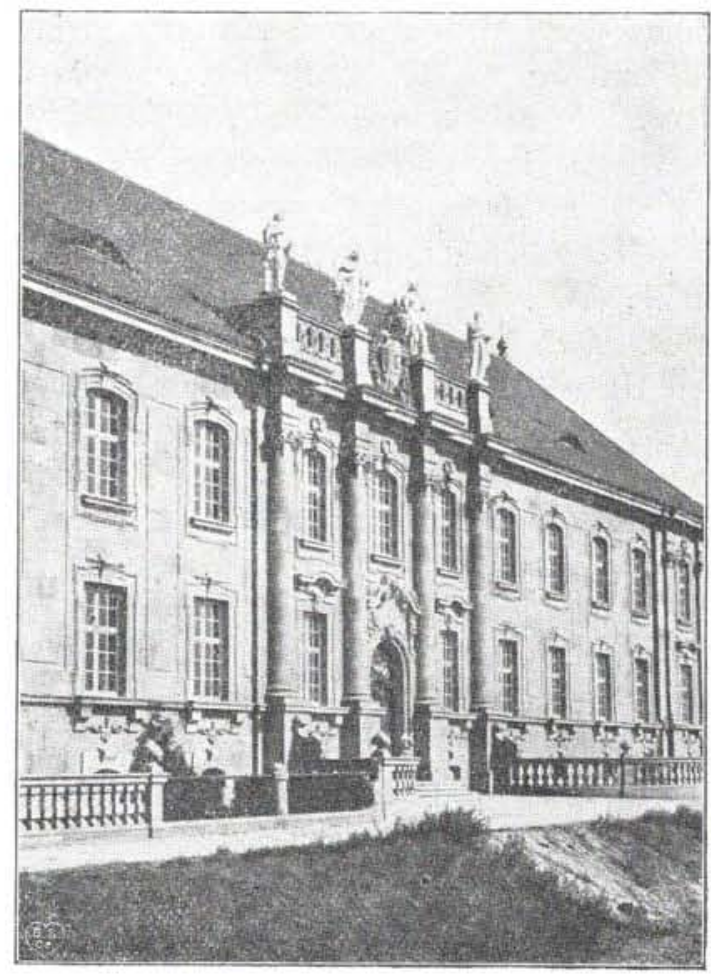

Abbildung 5. Mittelrisalit und Hauptfront des Archivgebiudes.

Petzold und Düll die Modelle gefertigt haben, soll später noch besonders ausführlich gesprochen werden.

Der eine der oben genannten zwei Seitenflügel des Hauptgebäudes, der monumentale westliche an der Ecke Sodenund Hainstrasse gruppiert sich in einfacher, übersichtlicher Anordnung dem gleichfalls zweigeschossigen Verwaltungs- und Wohngebäude an, von diesem nur durch den zurückspringenden Verbindungsgang getrennt. 
Das Kgl. Bayer. Kreisarchiv in Bamberg und sein Neubau.; 203

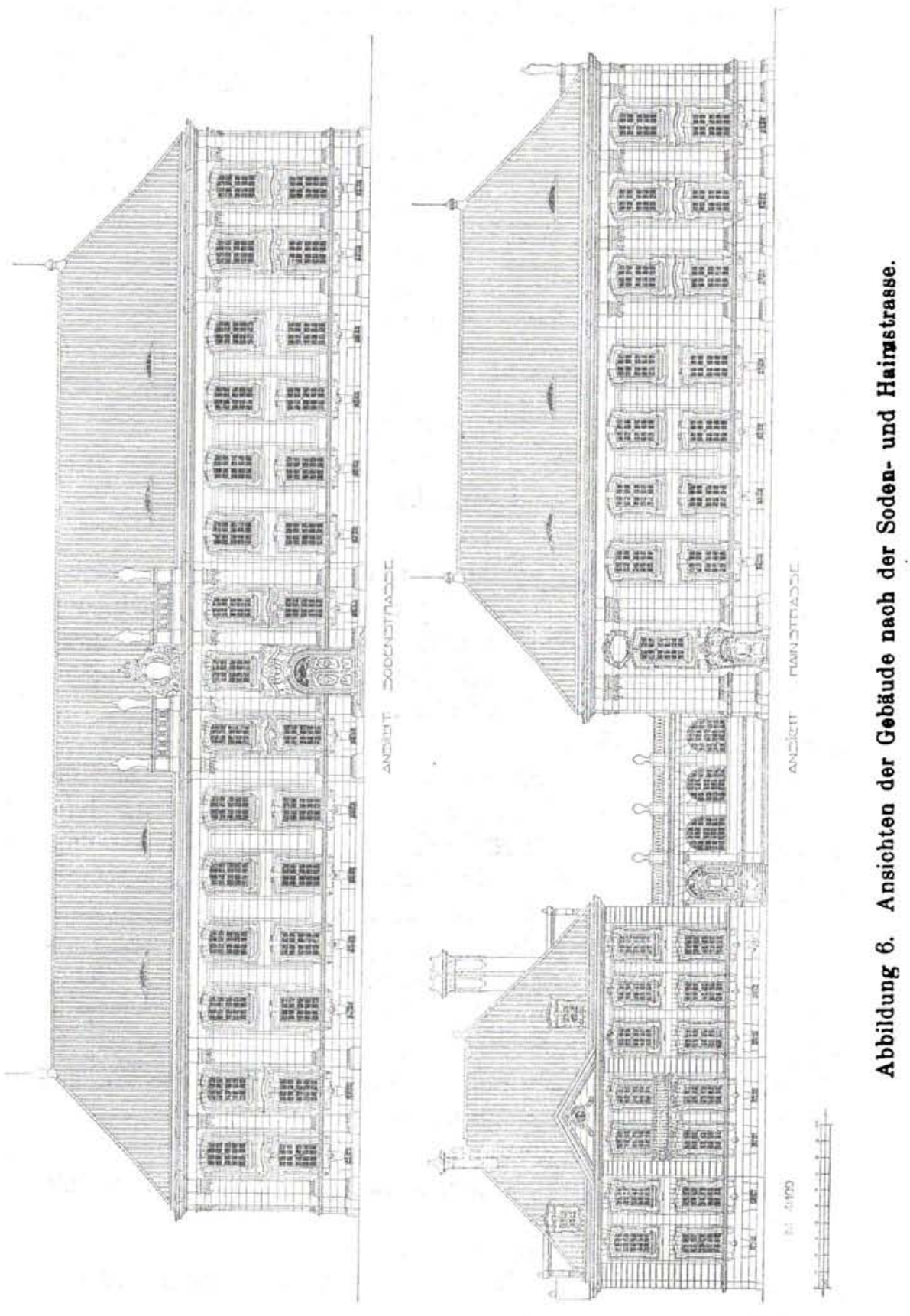


Ein grosses steiles, mit Biberschwänzen eingedecktes Satteldach setzt sich aut das Beständehaus mit seiner 8 Auffangstangen in Kupferstiefeln ausweisenden vorzüglichen Blitzableitungsanlage. Die Luftleitung besteht aus siebenfach gewundenem Kupferdraht, die Bodenleitungen, acht an der Zahl, bilden je eine im Grundwasser versenkte Kupferplatte und ein $7 \mathrm{~mm}$ starker Kupferdraht, welcher mit der Luftleitung auf $2,50 \mathrm{~m}$ über Terrain mittelst Ausschalter verbunden ist.

Nicht unerwähnt soll hier vor allem auch bleiben der seitlich und nach oben feuersichere Abschluss des Dachgeschosses vom Obergeschoss durch zwei starke Wände aus Tuffsteinmauerwerk "System Klein ${ }^{*}$, sowie durch eine nach „System Kücken“ feuersicher hergestellte Türe.

Was nun die Zugänge in das

Beständehaus

anlangt, befinden sich jene zum

Kellergeschoss

- zwei Treppen mit je 13 Stufen aus grünem Sandstein und zwei Eingangstüren aus Kiefernholz mit Stockrahmen, korbbogenförmigem Sturz und zwei Füllungen - in den Nebentreppenhäusern, welche da, wo Mitteltrakt und Seitenflügel zusammenstossen, eingebaut sind.

In den sämtlichen, ungemein trockenen und durch 50 unvergitterte Fenster tageshell belichteten Kellerabteilungen, welche im Bedarfsfalle jederzeit als völlig einwandfreie Aufstellungsräume dienen könnten, liegt ein Betonfussboden. Die Umfassungsmauern sind auf einer Höhe von $2,00 \mathrm{~m}$, die Zwischenmauern auf $30 \mathrm{~cm}$ über Kellerfussbodenoberkante in Portlandzementbeton, im übrigen in Backsteinmauerwerk hergestellt. Ueber sämtlichen Abteilungen mit Ausnahme von zwei solchen sind Tonnengewölbe, über letztere Kreuzgewölbe aus Backsteinen, welche auf Sandsteinpfeiler gestüzt sind, angebracht. Eine feuersichere Türe "System Kücken" schliesst endlich das Kellergeschoss des Beständehauses von dem Verbindungsgange, oder besser gesagt, von dem Raume unter demselben ab. In das

$$
\text { Erdgeschos s }
$$

gelangt man sowohl von den Strassenseiten, als vom Hof und dem Verbindungsgange aus. 
Eine Freitreppe aus blauem Granit führt zu dem in der Mitte der Hauptfront befindlichen Eingang in der Sodenstrasse. Die zweiflügliche, massive Eichenholztüre des prächtigen Hauptportals ist in üppiger Weise mit Bildhauerarbeiten verziert und mit kunstgeschmiedeten Winkelbändern und Türdrückern ausgestattet. Das Oberlicht in beweglichem Rahmen mit Klarglaseinlage hat ein reizend stilisiertes Kunstgitter, das ebenso wie zwei äussere Drücker reiche Vergoldung erkennen lässt.

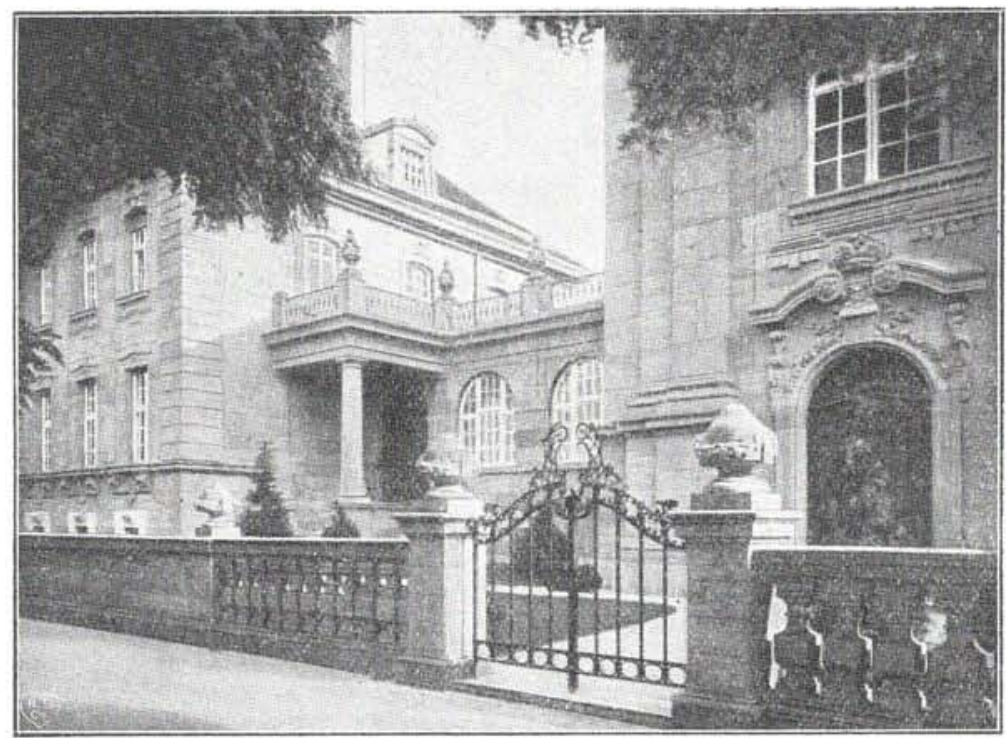

Abbildung 7. Teilansichten des Verwaltungsgebäudes mit dem Amtseingang, des Verbindungsganges und des Archivgebäudes.

Durch dieses Portal tritt man in das weite, hohe, eines ausserordentlich starken Lichteinfalls sich erfreuende Vestibül ein, zu dem eine profilierte gerade Differenztreppe mit sieben Stufen aus Granit zwischen zwei mit glatt bearbeiteten Sandsteinen verkleideten und mit Postamenten, Balustraden und einem Deckgesims versehenen Wangenmauern führt. Auf den Postamenten stehen in halber Grösse die vom Professor Hess gefertigten Gipsmodelle zu den Marmor-Statuen auf dem Hauptgiebel des Beständehauses. 
Von dem Vestibül aus erreicht man in gerader Linie und rechts und links ebenso rasch als bequem die sämtlichen $\mathrm{A} u \mathrm{f}-$ stellungsräume im Mittelbau und in den Seitenflügeln des Erdgeschosses, sowie die beiden zum Obergeschosse führenden Treppenhäuser mit ihren zwei direkt in den Hof gehenden. massiv aus Eichenholz gefertigten dreiflügeligen Toren mit je zwei Füllungen, Stockrahmen und Oberlicht mit gelber Kathedralglaseinlage.

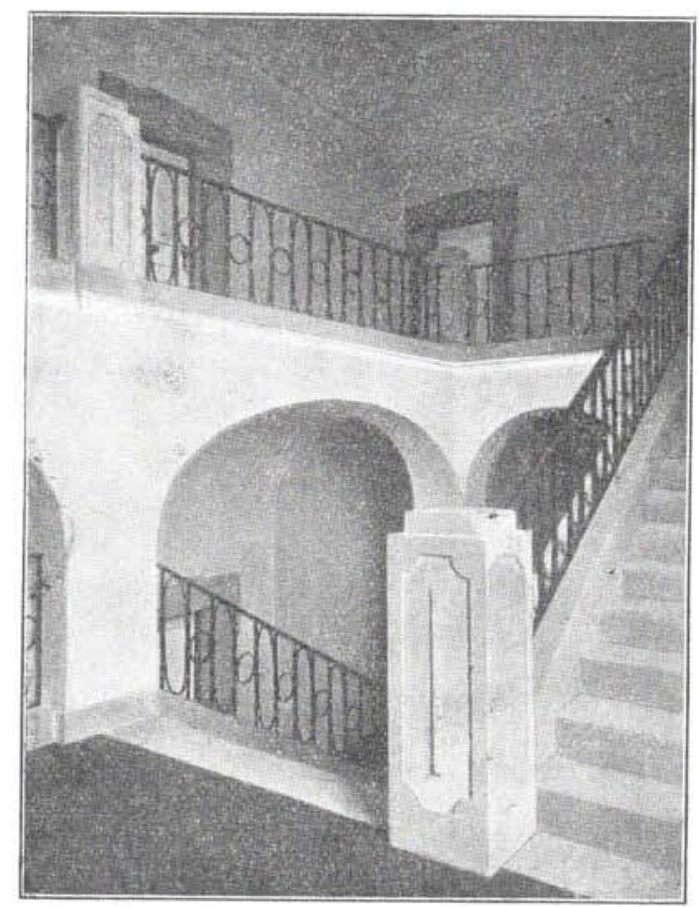

Abbildung 8. Treppenhaus im Archivgebäude.

Ein weiterer Zugang in das Erdgeschoss befindet sich in der Hainstrasse an der Stelle, wo der westliche Flügelbau sich dem zurückspringenden Verbindungsgange angliedert. Wir sehen da ein mässig hohes, gleichfalls mit Bildhauerarbeiten dekorativ ausgestattetes Portal mit einer schön geschnitzten und lasierten einflügeligen Türe aus Eichenholz, durch die man in das hohe, imposant wirkende, von zwei mäch- 
tigen Fenstern mit gelbem Kathedralglas beleuchtete HauptTreppenhaus kommt.

Eine Differenztreppe aus neun Granitstufen mit kunstgeschmiedetem Eisengeländer führt in der Höhe des Erdgeschosses zu einem weiten, geräumigen Vorplatze, in welchen links der Verbindungsgang mündet und von dem aus rechts durch eine zweiflügelige, feuersichere Asbest-Türe mit Türstock aus profiliertem Sandstein wiederum sämtliche Archivlokale des Erd-

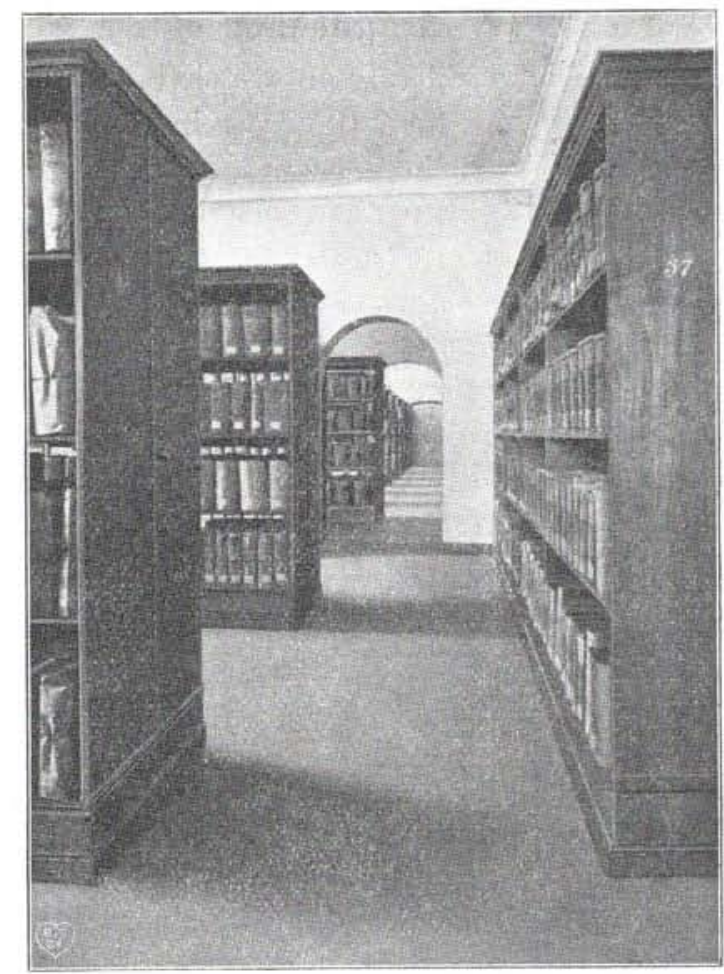

Abbildung 9. Durchblick im Erdgeschoss des Archivgebäudes (Aktensüle).

geschosses zu erreichen sind. Hier wird letzteres mit dem Obergeschosse des westlichen, monumentalen Seitenflügels durch eine kühn angelegte, gewendelt, freie tragende Granittreppe mit 28 profilierten Stufen, einer ebenfalls freitragenden Podestplatte aus Granit und einem kunstgeschmiedeten eisernen 
Handgeländer verbunden, während, wie schon berichtet, in dem mächtigen, $66 \mathrm{~m}$ langen Mittelhau die Verbindung mit dem Obergeschosse durch zwei Stockwerkstreppen mit zwei Läufen zu je 14 Stufen, Wangen und Postamenten aus grünem Sandstein hergestellt ist.

Die besonders in Gelehrtenkreisen eine hohe Wertung findenden Bestände des $k$. Kreisarchives verteilen sich in beiden Geschossen des prächtigen Hauptbaues folgendermassen:

\section{Im Erdgeschosse}

mit seinen 4,24 m hohen Sälen, von welchen die nahezu $200 \mathrm{qm}$ grossen mit je vier auf mächtigen Steinpfeilern im Kellergeschosse ruhenden Eisensäulen - aus Winkeleisen montiert und mit Rabitz ummantelt, sowie nach oben mit Stuck und buntfarbiger Malerei verziert - ausgerüstet sind, lagern in den immer senkrecht zur Fensterachse oder dem Pfeilermittel stehenden Regalen:

1. Der vor dem Umzuge neugebildete, jetzt schon $5(100$ Bände starke Amtsbücherselekt mit sämtlichen HochstiftBambergschen und Markgräflich Brandenburg-Bayreuthschen Sal-, Lager- und Grundbüchern, Urbaren, Zins-, Gilt-, Weisat-, Steuer-, Lehen-, Zehent- etc. Büchern;

2. die bischöflichen Kopial- und Privilergien-Bücher; die Konsens-, Pflicht-, Bestallungs-, Besoldungs-, Rats-, Missivund Geleits-Bücher;

3. die bischöflichen Wahl- and Huldigungs- $\Lambda$ kten, die kaiserlichen Belehnungen, die Erb-Ober- und Unterämter;

4. $200 \mathrm{Faszikel}$ Verordnungen und Dekrete;

5. die Regierungs-, Statthalterei-, Kanzlar-, Hofkammer-, Obereinnahm-, Oberjägermeisteramts-, Oberstallmeisteramts-, Obermarschallamts-Akten;

6. dit Weihbischofs-, Vikariats-, Reformations- etc. Akten;

7. die besonders zahlreichen Akten, Protokolle, Rezessbücher, Statuten, Kopialbücher und Kalendarien des Domkapitels; die Archivalien der Dompropstei, des Dekanats-und Konsistorialgerichts etc. etc.

8. die Akten der Kollegiatstifte, Klöster und Pfarreien;

9. die Universitäts- und Schul-Akten;

10. der ausserordentlich wertvolle Bestand der Reichstagsakten 
Bamberger und Brandenburger Provenienz, sowie der Reichs. korrespondenz;

11. 2534 Bände und Faszikel fränkischer Kreisakten, wie: Kreisabschiede, Kreistagsakten, Kreisprotokolle, Kreisrezesse, Militaria, Matrikular-Akten, Kreiskorrespondenz, Korrespondenz mit den kaiserlichen Gesandten und Mlinistern beim fränk. Kreis, Promotionsak ten, Relationen der Bambergischen Kreisgesandtschaft mit Original-Reskripten, Brandenburgs Beziehungen zum fränkischen Kreis, Allianzrezesse des letzteren, Münzakten und Münzrezesse etc. etc.

(Nicht weniger als nahezu 400 Bände Kreisakten Bamberger Provenienz, nämlich die Akten des Bamberger Direktorial-Archives, sind bedauerlicherweise und ganz systemwidrig vor mehr als 20 Jahren schon von hier nach Nürnberg transferiert worden.) -

12. 838 Bände, bezw. Faszik el Kriegs-, Bundes- und FehdeAkten, betreffend den Bauernkrieg, Markgräflichen Krieg, 7 jährigen Krieg, 30jährigen Krieg Bamberger- und Bayreuther Serie etc., dann den Schwäbischen Bund, Landsberger, Fränkischen und Kaiserlichen Bund, Union und Liga otc. etc.;

13. die Adelsakten;

14. der grosse Bestand von Akten der Fränkischen Reichsritterschaft, insbesonders der Kantone: Gebirg. Steigerwald und Baunach;

15. die Archivalien über hochstiftische Besitzungen und Lehen in Kärnthen, Steiermark, Tirol und Niederösterreich;

16. die älteren Forst-, Hut- Weide-, und Triftakten;

17. Bestände, wie: Briefe und Korrespondenzen einzelner hervorragender Personen, Brandenburger Fürsten, Bamberger Bischöfe, der Bamberger Regierung mit der Römischen Kurie etc. etc.; Historischer Katalog, Manuskriptensammlung etc. etc.;

18. das vor dem Unzug in den Neubau zu einem besonderen grossen Rechnungsarchiv vereinigte, drei Säle füllende Gesamtrechnungsmaterial vom Jahre $1414 \mathrm{ab}$;

19. der umfangreiche, noch ungeordnete handschriftliche und sonstige aus Karten und Plänen, einer Münz- und Archivalische Zeitschrift. Neue Folge. XV. 
Siegel-Sammlung etc. etc. bestehende Nachlass des im Jahr 1903 in Bamberg verstorbenen, als Förderer und Freund von Kunst und Wissenschaft wohlbekannten Emil Marschalk Freiherrn v. Ostheim. (Eingehende Beschreibung und kritische Würdigung dieses Legates soll in einem der nächsten Bände der Archivalischen Zeitschrift niedergelegt werden);

20. die von den Gemeinden unter Eigentumsrorbehalt zur Vorwahrung übergebenen Archivbestände. - Unter Archivalien im Sinne der Ministerialentschliessung vom 8 . A ugust 1906 N. 17512, die Behebung der bei den gemeindlichen Archiven noch immer bestehenden Missstände betr., sind alle Urkunden, Schriftstücke und Drucksachen zu verstehen, denen allgemeine oder wirtschaftlich geschichtliche Bedeutung zukommt und die für den laufenden Dienst nicht mehr benötigt erscheinen. In Betracht kommen hier vorzugsweise folgende Gruppen von Archivalien:

Urkunden auf Pergament und Papier, besonders Kauf- Tausch-, Gilt- und Stiftungsbriefe;

Grund-, Sal-, Lager-, Gilt-, Schatzungs- und Lehenbücher ;

Güter-, Flur-, Wald- und Markungsbeschreibungen; Befehl-, Protokoll-, Beschluss- und Urteilsbücher, Gerichtsbücher- und Akten;

statistische Aufstellungen, wie Büıgerverzeichnisse, Erntenachweise u. dgl.; Akten über Innungen und Zünfte; Rechnungen aller Art;

Verhandlungen über Erwerb, Verkauf, Verwaltung, Verteilung, Verpachtung von Gemeindeeigentum, über Gemeinderechte, Gemeindeprivilegien, hierauf bezügliche Streitigkeiten; Akten über Wege-, Wasser-, Forstsachen ;

Akten über Kirchen- und Schulsachen, sodann über eigenartige örtliche Feste;

Gemeinde- und Ortspläne, Orts-Chroniken, ältere Zeitungssammlungen und Flugblätter, Abbildungen des Gemeindewappens etc. etc.

Zu den gleichfalls 4,24 $\mathrm{m}$ hohen und wie im Erdgescbosse mit rabitzummantelten Eisensäulen ausgerüsteten Sälen des 


\section{Obergeschosses}

übergehend, wird daselbst vor allem der ursprünglich ungemein reiche, im Lauf der Zeit aber durch zwangsweise Abgabe der ältesten und kostbarsten Stücke im Wert bedeutend reduzierte Urkundenschatz mit ca. $i(0) 0()$ Dokumenten sorglich behütet. Er beansprucht mit seinen 458 belegten und $i 0$ in Reserve stehenden Schränken mit je 2 Fächern den ganzen mächtigen Raum des architektonisch am vornehmsten ausgestalteten Mit tel-

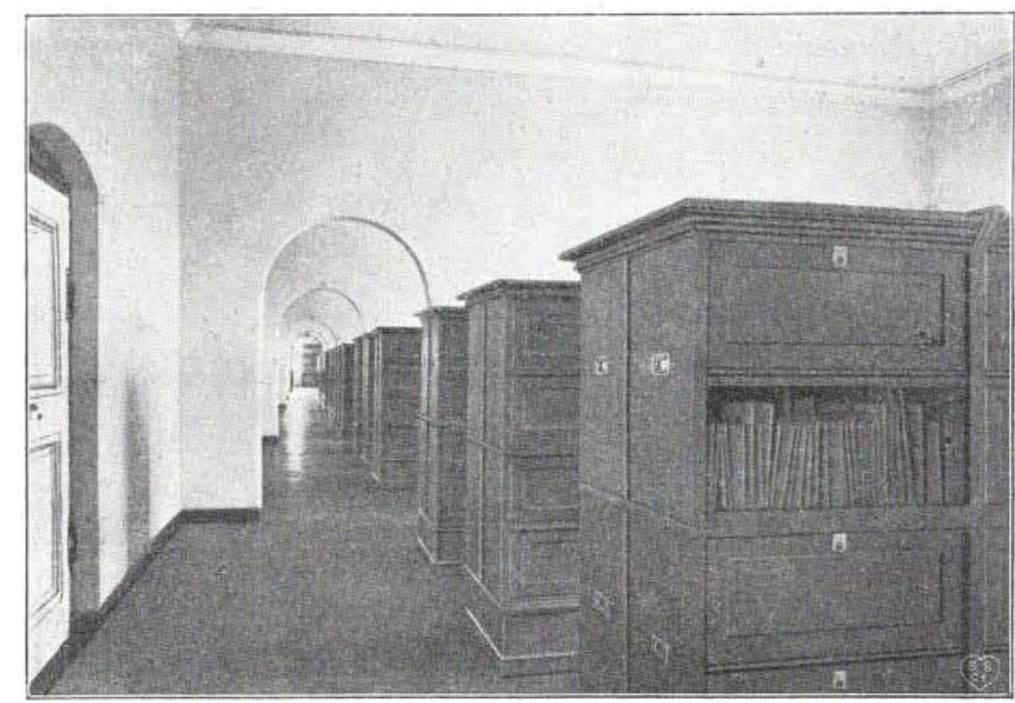

Abbildung 10. Durchblick im Obergeschoss des Archivgebäudes (Urkundensäle).

traktes mit Ausnahme eines einzigen, zur Aufnahme des wichtigen Bamberger Stadtarchives bestiminten, nach Norden gegen die Hofseite gelegenen schornen und geräumigen Saales.

Die massiv aus Eichenholz gefertigten, noch näher zu heschreibenden $\mathrm{Schreine,} \mathrm{für} \mathrm{welche} \mathrm{mit} \mathrm{Rücksicht} \mathrm{auf} \mathrm{ihre}$ möglichst günstige Aufstellung eine bestimmte Abmessung der Fensterachsen - verschieden von jener fürdie Aktenregale - erfolgte, sind mit scharf sich abhebenden in hellblauer Farbe gemalten Aufschriften versehen, welche die zahlreichen Serien der Stück für Stück eingelagerten Urkunden 
namhaft machen. Ausgeschieden nach Dokumenten Bamberger und Brandenburger Provenienz folgen die Serien, wie nachsteht, aufeinander:

\section{A Bamberg:}

Kaiser-Urkunden - Papst-Urkunden - Bischofs-Urkunden - Weihbischofs-Urkunden - Domkapitel - Dompropstei Kollegiatstifte - Klöster - Pfarreien - Wohltätigkeitsanstalten - Bündnisse und Verträge - Bauernkrieg - LehenUrkunden - Forst-Urkunden - Handwerksordnungen Judenschutzbriefe - Schuldverschreibungen - Kärnthen Reichsritterschaft - Nürnberger Patriziat - Westphälisches Freigericht - Stadt Bamberg - Hochstiftische Orte.

B. Brandenburg:

Märkgräfliche Orte; - die sog. „Brandenburger Urkunden“, eine zu den bedeutendsten Archivteilen zählende Sammlung von Dokumenten, betr. das hochfürstliche Haus Brandenburg, seine Beziehungen zu anderen fürstlichen Häusern, Reichs. ständen und Städten, dann zu Frankreich, England, Russland, Holland Dänemark, Schweden, Venedig etc.; ferner Landtagsund Landschaftssachen, Reichsbelehnungen, Huldigungsrezesse des Adels und der Städte, das kaiserliche Landgericht in Nürnberg, Rottweil und Schwabach, das Bergwerks-, Salinen- und Postwesen; die Städte Berlin, Köln a. d. Spree und Garz a. d. Oder etc. etc.; Klöster - Pfarreien - Wohltätigkeitsanstalten - Testamente - Lehen - Nürnberger Pat riziat.

Den Schluss bildet der umfangreiche, der Provenienz nach nicht ausgeschiedene Selekt der

$$
15000 \mathrm{Ad} \theta \mathrm{ls} \text { urk unden, }
$$

zu deren Unterbringung allein $100 \mathrm{Sch}$ ränke oder $200 \mathrm{~L}\lrcorner \mathrm{ad}$ en benötigt waren.

Die beiden Flügelbauten des Obergeschosses bergen in der Hauptsache

1. die aus dem Plassenburger Archive stammenden, in der Zeit von 1812 bis 1816 nach Bamberg transferierten sog. "Brandenburger Akten", wie:

Gemeinbücher - Bestallungs- und Besoldungsbücher

- Schuld- und Rechnungsbücher - Hofgerichtsbücher 
- Forst- und Jagdbücher - vermischte Landtagsakten und Protokolle - Landschaftsakten - Staatsverträge Rezessbücher - Ritterschaftliche Lehen- und Steuersachen - die sog. Sächsischen Bücher - Aemterbeschreibungen - Verordnungen - Lehensakten Städtetagsakten - Jülichsche Successionsakten - Kaiserliche Kommissionsakten - Heilsbronner LandesteilungsAkten - Differenzakten - Kloster- und Pfarreiakten 540 Bände Collectanea etc. etc.

2. das erst im Jahre 1905 von der K. Regierung von Oberfranken anher extradierte, nur allzu lange einer intensiven Ausnützung zu wissenschaftlichen und Verwaltungszwecken entzogen gewesene, leider noch ungeordnete markgräfliche Hofka mmerarchiv mit nachstehenden Aktengruppen:

fürstliche Appanagen, Aussteuer und Subsidien fürstliche Hausordnungen - fürstliche Reisen fürstliche Verlassenschaften - fürstliche Begräbnisse genealogische Nachrichten - Orden, Titel und Wappen - Inventare der Schlösser, dann des Theaters und Naturalienkabinets in Bayreuth - Reichssachen Landesverfassung - Regierungsveränderungen - Landschaftskollegium - Landschaftssyndikate - Landschaftsobereinnahme - Landständische Rezesse Reichsritterschaftliche Generalakten und Rezesse Ritterschaftliche Differenzen - Einigungen und Verträge - Aemterorganisation und Beamtenwesen Akten über Stadt und Amt Erlangen - Kirchenund Schulsachen (z. T. Konsistorialakten) - Akten des Klosters Heilsbronn - Stiftungen und Stipendien; Domänen-Akten: a) des vormaligen Fürstentums Bayreuth und zwar General- und Aemterakten b) Bamberger, Nürnberger und Würzburger Domänenakten - Bausachen (Hochbau, Weg- und Brückenbauten) - Bergpatente - Manufakturen und Fabriken - Statistik - Sanitätswesen - Militaria Schuldenwesen - 744 Fas zikel Lehenakten - Handlohn-, Zehent- und Giltwesen und zwar General- und Spezial-, bezw. Aemterakten - Frohnwesen - Umgeldund Zoll, Accis- und Stempelwesen - Steuersachen - 
endlich

Rechnungen, wie Bau- und Reparationsrechnungen die Veste Plassenburg betr., Rechnungen über sämtliche Garnisonseinrichtungskosten im Fürstentum Bayreuth, Haupt-Servis - Kassarechnungen, Haupt-Fourage-Geldrechnungen, Einquartierungsberechnungen, Erlanger Universitätsrechnungen, Forst- und Jagdrechnungen etc. etc.

3. die Plansammlung -

4. die sog. Antiquar-Registratur, i. e. das von den K. hreisregierungen von Ober- und Mittelfranken, den K. Bezirks-, Rent- und Forstämtern, sowie den K. Justiz-Behörden extradierte Material.

Verlassen wir nun das antragsgemäss nicht zu beleurhtende und mit keinerlei Heizanlage versehene Beständehaus, bei dessen Errichtung Alles, was die moderne Technik, was reiche Erfahrung und ängstliche Vorsicht zu bieten und zu ersinnen vermochte, um jede Gefährdung des herrlichen Baues durch Feuer, Wasser oder Feuchtigkeit hintanzuhalten, in Anwendung kam und wenden wir uns zunächst dem $12 \mathrm{~m}$ langen und $3 \mathrm{~m}$ breiten

$$
\text { Verbindungsgang }
$$

zu. Die Wände im

Kellergeschosse

desselben sind auf $2,00 \mathrm{~m} \mathrm{Höhe} \mathrm{aus} \mathrm{Portlandzementbeton,}$ im übrigen aus Backsteimmauerwerk hergestellt und über dem ganzen Raum ist ein Tonnengew ölbe mit Stichkappen an den vier Kellerfenstern angebracht.

Im Fussboden aus Beton liegt ein mit Eisenplatten abgedeckter Schacht, in welchem eine Wasseruhr und sämtliche Entleerungshähne für die Hauptstränge der weit verzweigten Wasserleitung sich befinden.

Eine Freitreppe mit 9 profilierten Stufen und einer Podestplatte aus blauem Granit führt von der Hainstrasse, bezw. dem Vorgarten daselbst durch eine massive, mit Bildhauerarbeiten verzierte Eichenholztüre in das 


$$
\text { Erdgeschoss, }
$$

dessen Haupt- und Hoffassaden aus Sandstein, die unterste Sockelschichte dagegen aus Muschelkalk bestehen.

Die Freitreppe ist überdeckt und bildet diese Ueberdeckung mit jener des Verbindungsganges (System "Secura“) die zur Dienstwohnung des Amtsvorstandes gehörige, von Steinpostamenten mit reizenden Vasen und kunstgeschmiedeten vergoldeten Eisengittern eingefasste grosse Veranda.

Im Erdgeschosse des nach der Strassen-, wie Hofseite mit sieben durch Fenster geschlossenen, weiten Bogen öffnungen, mit Kreuzgewölbe und Plattenbelag versehenen und, wie schon bemerkt, vom Beständehaus durch eine feuersichere Asbesttüre getrennten Verbindungsganges liegt zur linken Hand der Zugang zu den Amtslokalitäten im

\section{Verwaltungsgebäude.}

Dieser gleichfalls im Stil des Bamberger Barocks errichtete, mit der Hauptfront an der Hainstrasse stehende, $23 \mathrm{~m}$ lange und 15,6 $\mathrm{m}$ tiefe Bau erscheint in der Art der Ausführung dem Beständehaus konform und enthält wie letzteres Keller-, Erd-, Ober- und Dachgeschoss.

Die Grundrissform bildet ein Rechteck, an das sich ein Pavillon mit abgestumpften Ecken angliedert.

Die Hauptfassaden wurden bis Hauptgesims-Oberkante sammt den Giebeln aus prächtigem Hausteinmaterial, die Hoffassaden mit Ausnahme der Tür- und Fensterumrahmungen, Lisenen und des Hauptgesims, welche in Haustein behandelt sind, von Backsteinmauerwerk mit glattem, weissem Kalkmörtelverputz hergestellt.

Auf das Gebäude, das mit einer aus zwei Boden- und Luftleitungen und zwei Auffangsstangen bestehenden Blitzableitung versehen ist, setzt sich ein nach allen Seiten abgewalmtes Satteldach mit Doppeleindeckung in Biberschwänzen auf. Durch eine schwere eiserne Türe ist auch hier ein feuersicherer $A b$ schluss des Dachgeschosses von dem Obergeschoss geschaffen.

$\mathrm{Zu}$ dem mit einem Tonnengew ölbe überdeckten

$$
\text { Kellergeschoss }
$$

dessen Umfangs- und Zwischenmauern auf 2,00, bezw. $0,30 \mathrm{~m}$ über Fussbodenoberkante aus Portlandzementbeton errichtet 
sind, führt im Stiegenhause der Vorstandswohnung eine Treppe mit 14 geraden Stufen aus grünem Sandstein.

In das

\section{Erdgeschoss}

gelangt man sowohl von den gegen Norden und Osten liegenden zwei Hofseiten mit je einem besonderen Wohnungseingang für Vorstand und Diener, als von dem Verbindungsgange

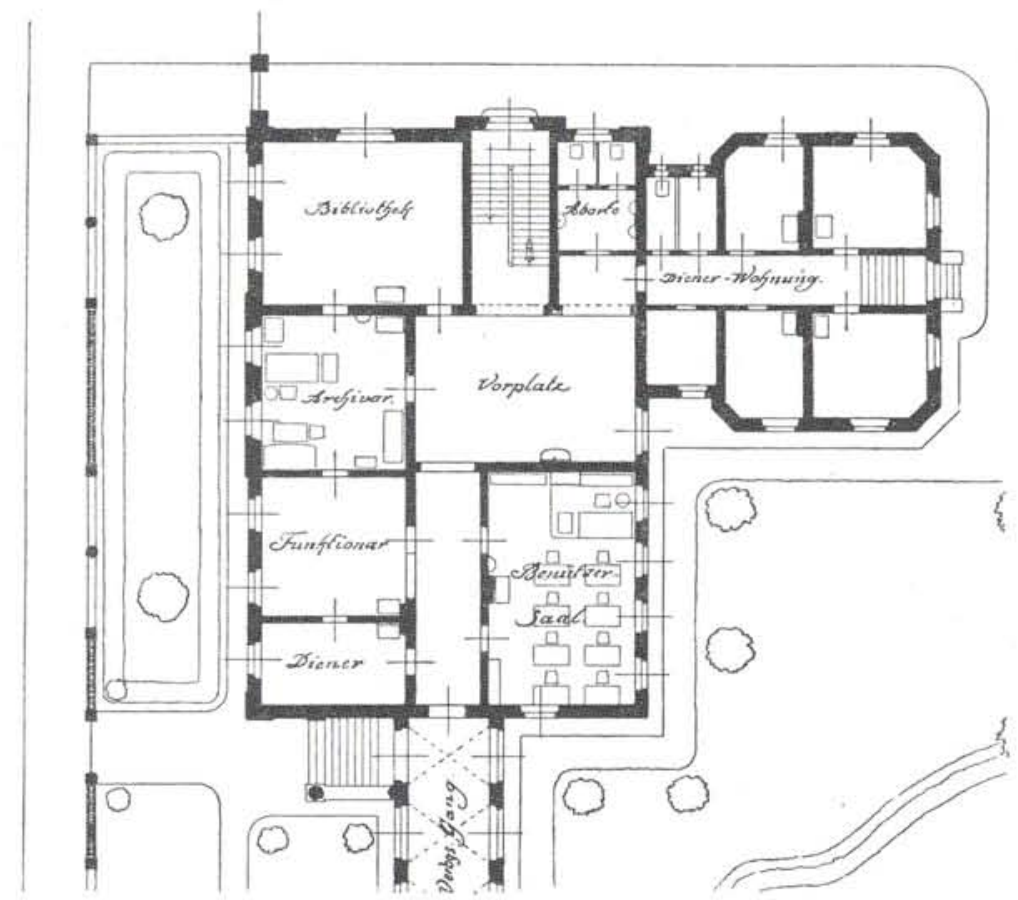

Abbildung 11. Plan des Verwaltungsgebäudes (Erdgeschoss und der Dienerwohnung).

aus. In letzterem wenden wir uns nach links und treten durch eine weissgestrichene breite Glastüre mit zwei Füllungen und Oberlicht in einem $8,68 \mathrm{~m}$ langen und $2,40 \mathrm{~m}$ breiten Gang, der in die grosse, nicht weniger als 53,26 qm Bodenfläche einnehmende Diele mündet.

Im Gang, wie in der Diele führen Türen $z$ u den Amtslokalitäten und zwar in ersterem, zunächst dem Eingang in 
das Zimmer des Archivdieners mit dem elektrischem Türaufzug, anstossend daran in die Kanzlei, woselbst der Funktionär seinen Platz hat und die ganze Manualregistratur untergebracht ist und diesen beiden läumen gegenüber zu dem in rückwärtiger ruhiger Lage mit schönem Ausblick auf die Hof- und Garten-Anlagen und Höhenzüge des Fränkischen Jura befindlichen Benützersaal, welcher seiner Zweckbestimmung bebesonders entsprechende Ausmasse, nämlich $9 \times 5,68 \mathrm{~m}$, sowie fünf nicht nur breite, sondern - bei einer Stockwerkshöhe von $4,24 \mathrm{~m}$ - naturgemäss auch hohe Fenster aufzuweisen hat.

Das mit dem Dienerzimmer und der Kanzlei in gleicher Flucht gegen die Hainstrasse liegende Vorstandszimmer und der mit demselben direkt verbundene, in der Nordwestecke des Erdgeschosses eingebaute 54,17 qm grosse Saal mit der Amtsbibliothek, dem Rüstzeug jeden Archivbetriebes, das besonders handgerecht zur Stelle sein muss, haben ihren Eingang von der Diele aus. Diese letztere, mit zum Teil wertvollen Portraits von Bamberger Fürstbischöfen, mit seltenen Wappentafeln, alten unter Glas und Rahmen befindlichen Karten, einer Ledermöbelgarnitur und einem ebenso schönen, als kostspieligen Marmorbrunnen ausgestattete Raum ist in gerader Richtung vom Treppenhaus der Vorstandswohnung durch eine Eichenholztüre in Stockrahmen und geschweiftem Kämpfer darüber abgeschlossen, während man von ihm aus rechts in den Pavillon mit der hübschen Wohnung des Archivdieners gelangt.

Zum Obergeschoss führt eine massive, braun gebeizte und lakierte Eichenholztreppe mit Parketpodest, Postamenten, $\checkmark$ asen und Balustraden aus Eichenholz, welche mit Bildhauerarbeiten verziert sind.

Gegen das Dachgeschoss finden wir auch bier im Verwa!tungsgebäude einen feuersicheren Abschluss:

Wände aus Backsteinmauerwerk mit Kalkmörtelputz, Decke massiv, System ,W abenstei ${ }^{*}$; zur Hälfte glatt verputzt mit einer Hohlkehle, zur Hälfte Kreuzgewölbe aus R a b i t z.

In den Dachboden selbst mit seinem gut geglätteten Gipsestrich (wie im Hauptgebäude) tritt man durch eine mit Querund Tragleisten versehene eiserne Türe zwischen 
Steingewänden. Der Dachstuhl .. ein Hängewerk mit eingeschobenem Sprengwerk - ist an den beiden Schmalseiten abgewalmt.

Von den Amtslokalititen ist ausser dem, Zimmer des Archiv-Vorstandes hesonders der Benütyersaal, in welchem der zweite Sekretär die Aufsicht führt, reich und rornehm ansgestattet. Erwähnt soll hier vor Allem werden der prächtigre Meissener Ofen in Elfenbeinton mit Delfterblau abgetönten

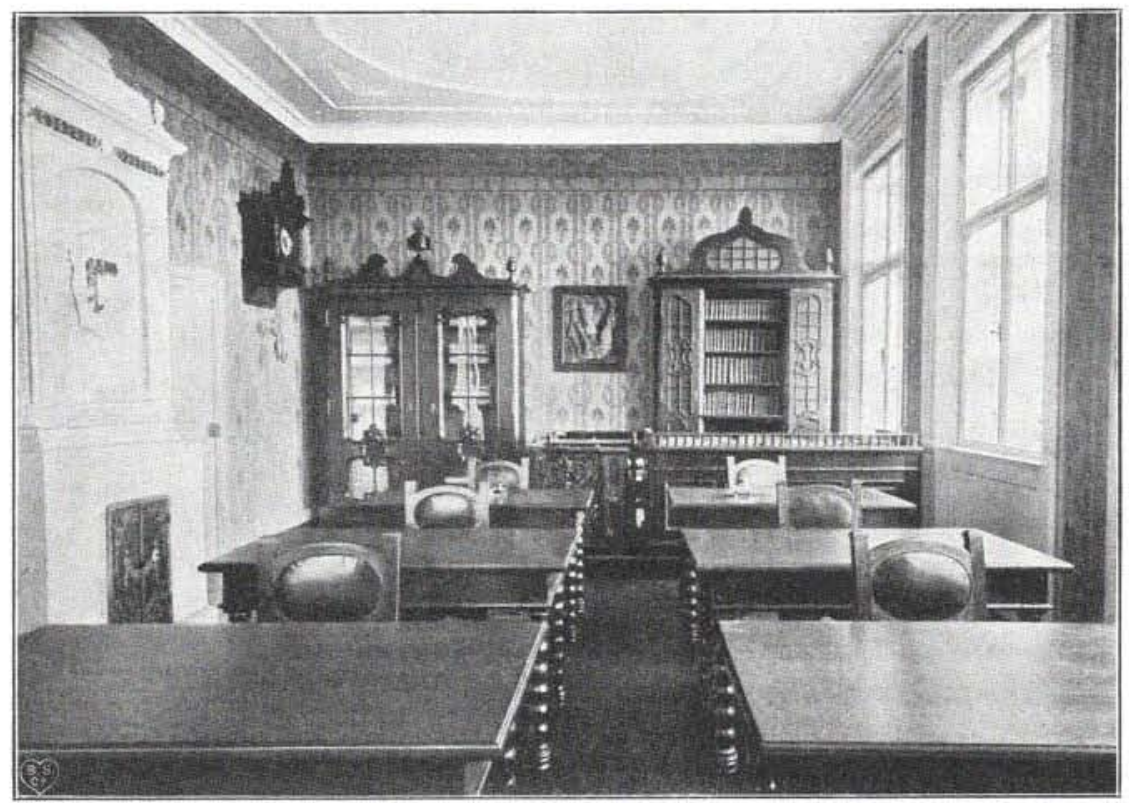

Abbildung 12. Der Archivbenützungssaal.

Verzierungen und dem farbigen Bayerischen Wappen; ein an die Wasserleitung angeschlossener, hervorragend zweckmässiger Wandbrunnen mit Steingutbecken und Brause; ein Podium mit massiver Eichenholz-Balustrade aus doppelseitig geschnitzten Balustern und einem rein rot geknüpften Teppich; ein auf dem Podium freistehender, 2,10 $\mathrm{m}$ langer und $1,10 \mathrm{~m}$ tiefer $\mathrm{Schreib-}$ tisch für den Sekretär, massiv Eichenholz, mit teilweiser Fournierung, geschnitzten Profil-Leisten, geschnittener massiver Füllung und breiten, häbschen Messing-Beschlägen; zwei mit 
Das Kgl. Bayer. Kreisarchiv in Bamberg und sein Neubau.

Bildhauerarbeiten verzierte, ebenfalls ganz massiv aus Eichenholz gearbeitete, mit durchgehenden Türen und sehr schönen Aufsätzen in Opalinverglasung versehene Schränke für die Repertorien und eine kleine Handbibliothek; acht Benützertische mit gedrehten Füssen, Schubladen etc. etc., gebeizt und mattiert; ebensoviele Benützerstühle in gleicher Ansführung - Eichenholz und silbergrauer Ton -, Sitze von Rohrgeflecht, Rücklehnen dagegen mit rotem Leder flach gepolstert; ein in Oel gemaltes wertvolles Bild Seiner Königlichen Hoheit das Prinzregenten in schön geschnitztem und reich vergoldeten schwerem Eichenholz-Rahmen; endlich eine Uhrgarnitur nebst Gehäuse, massiv Eichen, mit leichter Bildhauerarbeit und Patinavergoldung einzelner Teile.

Die Wände der Amtslokalitäten sind wie jene aller übrigen Räume des Erd- und Obergeschosses aus Backsteinmauerwerk mit Kalkmörtelputz hergestellt und entweder mit Leimfarbe in gelbem, grauem, auch grünem Ton getüncht, oder ein- und zweischlägig patroniert, bezw. mit ungemein dekorativ wirkenden Damastmustern in rotem oder gelbem Ton bemalt und mit Goldleisten ringsum verziert.

Sämtliche Decken - massive, feuersichere Wabensteindecken - wurden zum 'Teil einfach mit Kalkmörtel verputzt, zum Teil durch Stuck profile und Hohlkehlen noch besonders schön ausgestattet.

Bezüglich der Fussböden und ihres Belags ist bereits in der allgemeinen Beschreibung der verschiedenen Gebäudeteile des Gesamtkomplexes über Alles, was zu wissen nötig erscheint, ausführlich berichtet worden.

In der nördlichen Flucht des oben beschriebenen Verwaltungsgebäudes, im Abstand von 7,00 m von der Anwesensgrenze steht das $20,7 \mathrm{~m}$ lange und $6,00 \mathrm{~m}$ tiefe

Nebengebäude

mit der Waschküche und den zur Lagerung der Holz- und Kohlenvorräte des Amtes, Vorstandes und Dieners erforderlichen Räumen.

Die Umfassungsmauern sind aus Backsteinmauerwerk, die glatt und ohne Profil gearbeiteten, leicht gerillten $\mathrm{T}$ ü $\mathrm{r}$ - und Fensterumrahmungen wie Lisenen aus Sandstein der 
Medlitzer Brüche und das profilierte, mit vortretenden Balkonknöpfen versehene und mit Karbolineum gestrichene $\mathrm{Haupt}$ gesims aus Holz hergestellt. Der Sock el aus behauenen Sandsteinen der Umgegend hat Backsteinhintermauerung.

Gegen Hain- und Sodenstrasse sind vertiefte reizende

$$
\text { Vorgärten, }
$$

welche von einer aus Sandsteinsockel, Balustern, Steinsäulen mit Vasen, Deckgesims und koniferen Hecken bestehenden Einfriedigung umgeben sind, angelegt, während nach der Nord- und Ostseite gegen Felder und Wiesen der Gebäudekomplex von einer Mauer eingeschlossen ist, auf deren Sockel Pfeiler mit Zwischenbögen oder geschmiedeten eisernen Gittern aufgeführt sind. Die Pfeiler wurden mit Steinkapitälen, die Bögen mit Bieberschwänzen abgedeckt.

Der

\section{Hof}

mit erhöhten und vertieften, durch Steintreppen zu erreichenden und mit Vasen auf Postamenten geschmückten Zier-, dann Gemüsegärten ist nebst seinen zwei Zufahrten, welche nach der Hain- und Sodenstrasse mit je einem zweiflüglichen versperrbaren eisernen Tore zwischen Steinpfeilern abgeschlossen sind, chaussiert, die aus Kies und Sand gemachten Fusswege sind gewalzt.

Vielleicht bin ich mit vorstehender, nicht selten bis ins kleinste Detail gehender und alle archiv- wie bautechnischen Einzelheiten berücksichtigender Schilderung des Bamberger Archivneubaues der Aufgabe gerecht geworden, die ich mir gestellt habe und darf nunmehr mit der

$$
\text { inneren Einrichtung des Beständehauses }
$$

mich beschäftigen, wobei ich aber nicht etwa nur ganz allgemein die Gesichtspunkte, von denen aus die Art und Beschaffenheit unserer

\section{Urkundenschreine und Aktenregale}

beurteilt werden sollen, zu berühren habe, sondern eingehend über System und Konstruktion, $Z_{\text {weckmässigkeit und Kosten }}$ dieser wichtigsten Bestandteile einer Archiveinrichtung mich ver. breiten muss. 
Bei meinem Streben, nur das Beste für das von mir seit 16 Jahren schon verwaltete Kreisarchiv zu schaffen, bezw. in Anregung zu bringen, hat mich nicht etwa der Gedanke geleitet, es sollte jerler Archiv-Vorstand bei einem Neubau die Fachwelt immer mit etwas besonders Apartem, noch nie Dagewesenem überraschen; ich hatte mir auch nicht die Aufgabe gestellt, das „viel verhandelte Problem “ der besten und einwandfreiesten Urkundenverwahrung für alle möglichen Archive zu lösen; ich glaube eben an die Zweckmässigkeit eines Normal-Urkundenschrankes oder eines Normal-Aktenregales ebensowenig als an die Selbstverständlichkeit des Magazinsystems in allen Fällen von Archivneubauten. In gediegener, praktischer und dabei doch gefälliger Einfachheit wollte ich Schreine und Regale gestaltet wissen. Die Art und Beschaffenheit unserer Literalien - vorwiegend gebundene Bände - , die Zahl und Grösse unserer Urkunden, die Menge und Form ihrer Siegel, das Ergebnis genauer Messungen der grössten und kleinsten Tome wie Dokumente und die hierauf sich gründende Festlegung eines Durchschnittsmasses für die Höhe und Tiefe der Akten und Urkundenfächer - Ausmasse im Lichten - sollten von bestimmendem Einfluss auf die Konstruktion genannter Mobilien sein.

Einen „Typus" für jedes beliebige Archiv zu schaffen, nach einem für alle Verhältnisse passenden System zu suchen, möchte als verfehltes Unternehmen sich erweisen; die Eigenart der einzelnen Archive spricht dagegen und es wird uns auch kaum gelingen, bei den aus letzter Zeit stammenden Archiv neubauten Aktenregale und Urkundenschränke von gleicher Konstruktion und Beschaffenheit zu finden. Für das Bezirksarchiv in Strassburg z. B. sind nach dieser Richtung hin wesentlich andere Gesichtspunkte massgebend gewesen, als für das Stadtarchiv dortselbst; das Kreisarchiv Speyer ist, vielleicht zum Heile seiner Urkunden - ganz andere Wege als das Staatsarchiv in Düsseldorf gegangen; Dresden hat aus der Beibehaltung des "Lokalsystems" die allein möglichen Konsequenzen gezogen und das Preussische Hausarchiv in Charlottenburg ist nicht versucht gewesen, mit seiner Tradition $\mathrm{zu}$ brechen und die schon vor dem Neubau vorhanden gewesenen, nicht weniger als 4,00 m hohen prächtigen Aktenschränke und Bücherregale einem System zu opfern, das nur Geschosshöhen bis 2,50 oder $3,00 \mathrm{~m}$ angängig erscheinen lässt. 
Hier in Bamberg ist für die Aktenrepositorien auf meinen Antrag das bekannte Fächersystem in seiner schlichten, einfachen Konstruktion zur Annahme gelangt, wobei die Einlagoder Tragbretter uicht durch kostspielige Zahnleisten oder Hebelvorrich t ungen verstellbar gemacht, selbstverständlich auch nicht an den vertikalen Seiten- und $Z$ wischenwänden mittels eingekehlter Nuten befestiget sind, sondern auf starken Leisten aus Eichenholz ruhen, welche durch Messingschrauben mit kräftigen Köpfen an den senkrechten Teilbrettern festgemacht wurden. So lassen sich die Leisten mühelos und ohne erhebliche Schwierigkeiten jederzeit versetzen und die Zahl der Fächer eines Repositoriums kann auch auf diesem ungleich billigerem Wege je nach Bedarf eine Mehrung oder Minderung erfahren. Dies wäre aber nicht zu erzielen, wenn der Techniker seine Absicht, die Einlag- oder Tragbretter in die Seitenwände einzuschneiden, verwirklichet hätte.

Die Lösung der weiteren, zunächst an mich herangetretenen Frage, welche Holzart bei Herstellung der Regale zur Verwendung kommen soll, war in erster Linie durch die Höhe der zur Verfügung stehenden Mittel bedingt.

Ursprünglich glaubte ich mir Repositorien aus massiv Eichenbolz erbitten zu müssen. Auf Veranlassung des K. Landbauamtes liess ich dann drei verschiedene Kostenvoranschläge und zwar über Ausführung

a) in Massiveichenholz (laufender Meter $=36 \mathcal{M}$ ),

b) in Halbeichenholz, nämlich: äussere Wände, vordere

Kanten und Gesims in Eichenholz, Zwischenwände und Böden dagegen in Fichten holz (laufender Meter $=22$ AC.) und

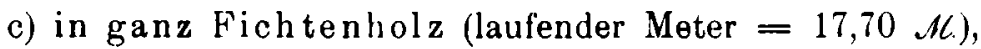
aufstellen.

Nach Vorlage derselben hat die K. Oberste Baubehörde dahin entschieden, dass für die Aktenregale die einfache Ausführung in Fichtenholz vollauf genüge und dass eine vom Kreisarchive beantragte eichenholzartige Beizung derselben unnötig erscheine. Es wurde von mir nämlich der Wunsch zum Ausdruck gebracht, den billigsten, i. e. Fichtenholzstellagen wenigstens durch reicher profilierte Gesimse ein gefälliges Aussehen zu geben, sie vor allem gegen Wurmfrass immunisieren und 
derartig beizen und behandeln lassen zu wollen, dass die Gesamtansichtsfläche - übereinstimmend mit den Urkundenschreinen in Eichenholzausführung sich zeigt. Erfreulicherweise ist später gegen die Beizung keinerlei Erinnerung mehr orhoben worden.

Die Zahl der benötigten Regale beträgt

$$
213 \mathrm{Stück}
$$

mit einer Gesamtlänge von

1422,02 la ufenden Metern.

Dieselben nehmen also eine Aufstellungslinie von nahezu $11 / 2$ Kilometer in Anspruch.

Zur Unterbringung der schon vorhandenen Bestände dienen

$$
170 \text { Stück }=1117,53 \text { laufende Meter, }
$$

von denen 77 auf Doppelstellagen $=748,20$ lfd. Meter und entfallen.

$$
93 \text { auf einfache Regale }=369,33 \text { lfd. Meter }
$$

In Reserve stehen zur Aufnahme des späteren Zuwachses 43 Stück $=304,49$ lfd. Meter.

nämlich: 20 Doppelstellagen $=210,40 \mathrm{lfd}$. Meter

und 23 einfache $=301,49 \mathrm{lfd}$. Meter

Von den 97 Doppelregalen haben

4 eine Länge von à $5,90 \mathrm{~m}=4 \bar{\imath}, 20 \mathrm{lfd}$. Meter

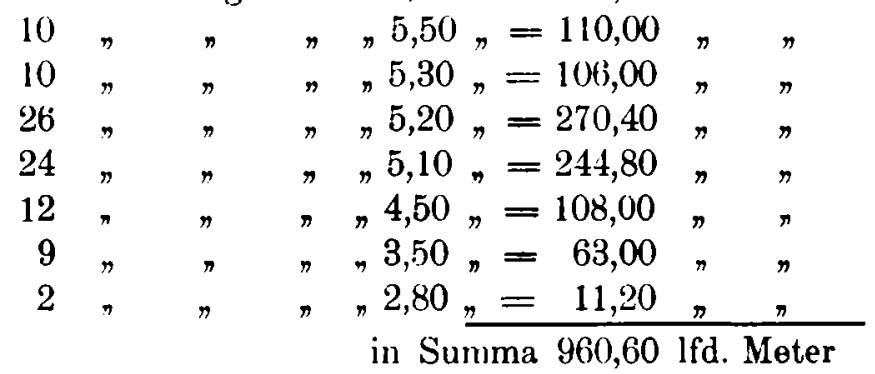

Die 116 einfachen Repositorie $n$ mit insgesamt: . . . . 461,42 lfd. Meter weisen aus:

33 Stiick mit einer Länge von $6,05-6,33 \mathrm{~m}$

$10, \pi, \pi, 5,10-5,45 \mathrm{~m}$

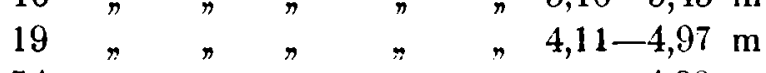

$54 \pi, \pi, \quad \pi$ unter $4,00 \mathrm{~m}$

Was die Höhe anlangt, welche die einzelnen Regale erhalten sollten, hatte ich schon unterm 8. Oktober 1903 mich 
dahin geäussert, es müsse an der unabweisbaren Forderung festgehalten werden, die Höhe so zu bemessen, dass selbst aus dem obersten Fache jedes Aktenstück und jeder noch so schwere Tom ohne Benützung einer Leiter, oder auch nur eines Trittes mühelos herausgenommen und wiederum eingestellt zu werden vermag. Demgemäss brachte ich eine Stellagenhöhe von

$$
2,50 \mathrm{~m}
$$

(inkl. Sockel und Gesims), vierfach geteilt, in Vorschlag, wobei die Höhe des einzelnen Faches mit $50 \mathrm{~cm}$ im Lichten und die 'Tiefe mit $40 \mathrm{~cm}$ dem Bedürfnisse entsprechend berechnot worden ist.

Zieht man nun die lichte Höhe des obersten Faches, die Holzstärke der Einlag- oder Tragbretter und die Höhe des Gesimses von der Gesamthöhe des Repositoriums ab, so ergibt sich eine Griffhöhe von nur $1,85 \mathrm{~m}$; es kann also selbst von einem kleinen Manne jedes im obersten Fache ruhende Archivale ohne Tritt bequem und leicht erreicht werden.

Die Grundlage für die genaue Bestimmung obiger Ausmasse haben wiederholt ron mir vorgenommene sorgfältige Messungen an den aus der fürstbischöflichen Zeit noch stammenden älteren wie an den viclen später beschalften Regalen, dann, wie schon einmal berichtet worden ist, ebensolche Messungen der grössten und der kleinsten Faszikel und gebundenen Tome gebildet.

Die Aufstellung sämtlicher mit fortlaufenden Nummern versehenen Doppelstellagen erfolgte genau in der $W$ eise, wie sie in Räumen nach dem Magazinsystem sich finden; sie stehen durchwegs immer senkrecht zur Fensterachse, oder dem Pfeilermittel und erfahren so von den zahlreichen hohen und ungewöhnlich breiten $(2,51 \times 1,64 \mathrm{~m})$ Fenstern eine äusserst intensive doppelseitige Belichtung.

Zwischen der Stirnseite der Regale und der Längsmauer mit den Fenstern läuft ein Gang von durchnittlich 1,15 m Breite und zwischen orsteren und der Innenseite der Säle ein solcher von rund $1,30 \mathrm{~m}$ Breite, während der Abstand der einzelnen Stellagenreihen voneinander durchschnittlich $1,25 \mathrm{~m}$ beträgt.

Zu den Schreinen für zweckmässige Verwahrung des reichen Urkundenschatzes übergehend, möchte ich zunächst nur ganz allgemein berichten, dass ich hier vollständig von der alten Tradition algewichen und redlich bemüht gewesen bin. 
etwas neues zu bringen und dem nicht leicht erreichbaren Ziele, eine in erster Linie praktische, jedwede Schädigung unersetzlichen Archivgutes ausschliessende und dabei doch wenig komplizierte Konstruktion auszudenken, wenigstens einigermassen nahezukommen. Ob ich mit dem Ergebnis meiner Bemühungen vor dem kritischen Auge des Fachmannes durchwegs bestehen werde, bleibt freilich noch abzuwarten; ron technischer Seite hat das mit überraschender Kunstfertigkeit von Herrn Oberstleutnant L. Werthmann im Massstab 1: 10 für die lichten Räume und 1:5 für die Holzstärke hergestellte Modell rückhaltslose Billigung gefunden, und ist der massgebende Referent der Obersten Baubehörde namentlich auch mit der von mir eindringlichst orbetenen Ausführung in Eichenholz einverstanden gewesen, nachdem die Wahl dieser besseren, gegen Feuer und sonstige zerstörende Einflüsse widerstandsfähigen Holzart mit Rücksicht auf den hohen Wert der Urkunden als völlig angemessen erscheinen dürfte.

Gleich hier soll konstatiert werden, dass bei der grossen Menge der im Kreisarchive Bamberg verwahrten Dokumente das für Speyer mit seinem ungleich geringeren Urkundenbestande hervorragend geeignete, auch sonst ganz vortreffliche System - Kästen mit je e in em Fache - selbstverständlich nicht in Frage kommen konnte. Die Zahl der erforderlichen Schränke inkl. Reserve würde ins Ungemessene gehen und bei Annahme eines Bestandes von ca. 75000 Urkunden auf 1100 bis 1200 Stück sich belaufen. Ich bin daher für Schreine mit je zwei übereinauderliegenden Fächern eingetreten, welche auch nach Festlegung ihrer Ausmasse - à $0,75 \mathrm{~m}$ breit $0,65 \mathrm{~m}$ hoch und $0,40 \mathrm{~m}$ tief - zur Aunahme gelangten.

Da immer zwei Kästen aufeinandergestellt und im ganzen $528 \mathrm{Stü} \dot{c} \mathbf{k}$

beschafft worden sind, ergeben sich:

$$
1 / \mathbf{s} \cdot 528 \times 0,75=198 \text { laufende Meter }
$$

Urkundenschränke mit $1,30 \mathrm{~m}$ Höhe $=257,4 \mathrm{qm}$ Ansichtsfläche derselben.

Ihre Aufstellung im Obergeschoss der Mittelpartie des Beständehauses erfolgte blockweise und zwar in 17 Blöcken mit je 24 Kästen und in 6 Blöcken mit je 20 solchen. 
Nicht unerwähnt darf hier bieiben, lass bei den unteren Schreinen der Suckel in Wegfall gekommen ist, weil auf Veranlassung des $\mathrm{K}$. Allgemeinen li: ichsarchivs pro Block immer ein 0,30 $\mathrm{m}$ hohes Podium, in Summa also 23 Podien angefertiget worden sind.

Diese Aenderung bietet $z$ woifelsohne eine nicht hoch genug einzuschätzende Gewähr, dass im Falle eines Brandes die durch schwere Eichensockel nicht belasteten Kästen leichter zu transportieren sind und damit einer Gefährdung durch Feuer rascher entzogen werden können.

Zur besseren Orientierung bezüglich Beschaffenheit und Konstruktion der die Aktenregale an schönheit weit überragenden, zudem äusserst vorteilhaft plazierten Lrkundenschränke mögen noch folgende, mehr ins Detail gehende Erläuterung('n dienen.

Aeussere Seitenwände, 'Türen, Gesims, Gurt, Lisenen und Sockel präsentieren sich in massiv Eichenholzausführung.

Die Türen sind. um ein Verziehen derselben zu verhüten. sogenannte Rahmentüren. Jede offnet sich nach abwärts, steht in horizontaler Lage fest und vermag so als Tischchen benützt zu werden. Die untere Fliiche der Türe ist abgerundet, bewegt sich in einer entsprechend creformten Nute in der unteren, bezw. Zwischenwand des liastens und wird mittels zwejer, in die Seitenwändo desselben eingreitender Sehraubenbolzen greführt und gehalten. Die Lager dieser Bolzen müssen natürlich mit eingelegten Eisenplatten wesentlich verstärkt werden. Bei geiffneter, bezw. heruntergclassener 'Türe gleicht sich deren innere Fläche mit der unteren (immeren) Fachwand ab, was nur möglich erscheint, weni die letztere stäker grehalten ist, als die erstere. Selbstverständlich sind, un ein rasches Fortschaffen der Schreine in stunden der Yot und Gefahr betätigen zu können, an den Seitenwänden derselben kraftige Handhaben eingelassen.

Die Lagerung der Urkunden vollzieht sich auch im Kreisarchive Bamberg in einer allen Anforderungen der Jetztzeit entsprechenden, insbesondere jede Schädigung der Siegel durch I) ruck etc. völlig ausschliessenden Weise.

Die bisher ïblich gewesene Bildung von fest zusammengeschnürten Päcken oder Faszikeln ist strengstens verpönt, jedes einzelne Dokument wird in einem couvertartigen steifen $\mathrm{Cm}$ - 
schlang aus starkem 'l'ekturpapier verwahrt und steht - von einzelne'n ungew öhnlich grossen Kaiserurkunden abgesehen - immer senkrecht im Kasten, desen Fächer durch je eine in der Mitte derselben befindliche kleine Zwischenwand geteilt sind.

Die Verschiedenheit in der Grösse der Urkunden machte es nötig, dass nicht weniger als vier, in den $A$ usmassen voneinander abweichende Ums chl ag formate $(29 \times 24 \mathrm{~cm}$; $30 \times 25 \mathrm{~cm} ; 36 \times 30 \mathrm{~cm}$ und $42 \times 32 \mathrm{~cm})$ angefertigt werden mussten.

An Signaturen finden sich auf der linken Seite der Umschläge und zwar in der oberen Ecke die Bezeichnung des Amtes: „Kreisarchiv Bamberg“ und die Nummer des Repertoriums, wie der Urkunde und in der unteren Ecke jene des Saales und des Kastenfaches.

Was endlich die Kosten für Herstellung der wegen ihrer sorgfältigen und gediegenen Ausführung besonders günstig beurteilten Urkundenschreine anlangt, beziffern sich dieselben auf rund $21120 \mathscr{M}$, während - um dies nachträglich noch festzustellen - die Aktenregale mit einer Ansichtsfläche von $3555 \mathrm{qm}$ einen Aufwand von 25169,75 Kh. verursacht haben.

Rechnet man zu diesen $46289,75 \mathscr{K}$ noch den Kostenbedarf für die Ausstattung der Bureaulokalitäten und des Benützersaales, sowie jenen für den grossen Umzung, so ergibt sich für die Innere Einrichtung des Beständehauses und der Amtsräume im Verwaltungsgebäude die Gesamtkostensumme von

\section{K 75 \&}

Zum Schlusse obliegt mir noch, ein bei Beschreibung der Aussenarchitektur des Hauptgebäudes gegebenes Wort einzulösen, nämlich

über die aus dem Atelier des Prof. A. Hess in München stammenden, wohl den schönsten Schmuck der Mittelpartie des Archivbaues bildenden 4 il on umentalfiguren besonders ausführlich mich zu verbreiten.

Im Vollzuge privater Weisungen des Herrn Referenten an der Obersten Baubehörde, für diese Figuren Persönlichkeiten in Vorschlag zu bringen, welche in innigster Beziehung zu den Hauptbestandteilen des Kreisarchives stehen, hatte ich schon im Frühjahre 1902 zunächst die Anschauung vertreten, dass eine 
Auswahl solcher historischer Persönlichkeiten allzu grossen, kaum zu überwindenden Schwierigkeiten begegnen möchte und dass es sich daher empfehlen dürfte, Typen zu wählen, bezüglich deren ich sodann den gutachtlichen Antrag unterbreitete, ins Auge fassen zu wollen:

1. einen Fürstbisch of

mit Rücksicht auf das hier verwahrte „Hochstift Bambergische Archiv";

2. einen Markgrafen der Kulmbacher Linio im Hinblick auf das gleichfalls hier befindliche „Plassenburger Haus- und Staatsarchiv“, i. e. das Archiv des Markgrafentums Brandenburg - Bayreuth - Kulmbach;

3. einen Vertreter der Reichsritterschaft wegen der in Bamberg lagernden reichen Bestände, welche auf die drei Ritterkantone: Steigerwald, Baunach und Gebürg sich beziehen;

4. einen Repräsentanten der vier grossen Abteien: Michaelsberg bei Bamberg, Ebrach, Banz und Langheim, sowie der vielen anderen Klöster in den beiden Fürstentümern Bamberg und Brandenburg - Bayreuth, deren Archivalien einen breiten Raum im hiesigen Archive einnehmen.

Auf diesen meinen näher begründeten Standpunkt wollte ich auch im Spätherbst 1902 wieder zurückkommen. Angesichts der in vorliegender Frage bisher immer ganz bestimmt kundgegebenen Willensmeinung des höchsten technischen Referenten glaubte ich aber meinen Antrag nicht weiter mehr aufrecht erhalten, vielmehr versuchen zu sollen, nun doch geschichtliche Personen heranzuziehen.

In erster Linie fiel meine Wahl auf

Lothar Franz von Schönborn, Bischof von Bamberg und Erzbischof von Mainz 1693-1729,

den Erbauer der neuen Residenz in Bamberg, in welcher unsere vielbenützten Archive nahezu 200 Jahre herbergten. Noch heute spricht man am $R \mathrm{~h} \theta$ in und am Main von den Schönbornzoiten und will damit eine Generation be- 
zeichnen, in der das geistliche Fürstentum seine grösste Macht und seinen höchsten Glanz entfaltete.

Lothar Franz begann in Bamberg auf der Stufenleiter der kirchlichen Würden emporzusteigen. Hier wurde er zuerst (1681) als vollberechtigtes Mitglied in das Domkapitel aufgenommen und bald darauf mit der Würde eines Scholastikus ausgezeichnet. Auch zu Würzburg und in Mainz erhielt er eine Kanonikerstelle.

Seine Geschicklichkeit in diplomatischen Geschäften bewies er auf den Fränkischen Kreistagen, welchen er im Auftrag des Bamberger Bischofs Marquard Sebastian Schenk von Stauffenberg beiwohnte. Dieser gewann immer grösseres Zutrauen zu Lothar Franz und ernannte ihn zuletzt zum Präsidenten seines Hofrates. In dieser Stellung fand letzterer Gelegenheit, sich die Kenntnisse anzueignen, die unentbehrlich für einen tüchtigen Regenten waren.

Nach dem Ableben Bischofs Marquard Sebastian wurde Lothar Franz von Schönborn 1693 zum Bisch of von Bamberg, am 3. September 1694 zum Koadjutor von Mainz und am 30. März des folgenden Jahres zum Erzbischof von Mainz erwählt. Er hatte also von nun an zwei geistliche Staaten zu verwalten, die, wenn auch durch den Main miteinander verbunden, doch im übrigen wenig Gemeinsames besassen.

Als Bischof von Bamberg war Lothar Franz berufen, den Vorsitz auf den Fränkischen Kreisversammlungen zu führen und als Beherrscher des mächtigen Erzstifts hatte er als erster Kurfürsi die Reichstage zu leiten, als Erzkanzler zu fungieren und die Reichsstände dem Kaiser gegenüber zu vertreten.

Vor allem war er auch ein begeisterter Verehrer der Kunst. Sie bildete für ihn ein Heiligtum, in das er sich, besonders bei zunehmendem Alter, aus den Händeln der Politik gerne zurückgezogen hat.

Die einzelnen Glieder der Schönbornschen Familie huldigten verschiedenen Neigungen, allen gemeinsam war aber die Liebe zur Baukunst und jedes von ihnen hat zum mindesten $e$ in bedeutendes Werk geschaffen.

Die Bautätigkeit des hochsinnigen Fürsten Lothar Franz beginnt mit der Zeit, da er zum Bis chof von $\mathrm{Bamberg}$ erhoben worden ist. Als seine bedeutsamste Schöpfung hat ohne 
Zweifel das von Bamberg in wenigen Stunden zu erreichende Schlois Weissenstein hei Pommersfelden zu gelten, ein Baudenkmal ersten Ranges. das in der Geschichte des Deutschen Barocks an hervorragender Stelle steht.

Seine Lust zum Bauen hat aber noch eine Reihe anderer Werke hervorgerufen, so namentlich das Residenzschloss in Bamberg. Hier beschränkte sich die Tätigkeit des Bauherrn auf die zwei dem Dom zunächst liegenden Trakte, welche rom Grund aus neu aufgeführt wurden. Gewaltig ragt aus dem abschüssigen Terrain das östliche Ende des Vorderbaues. woselbst in den Hochparterre- und Souterrainlokalitaten die Bamberger Archive bis zum Herbst $190 \bar{s}$ untergebracht waren, empor und findet in einem turmähnlichen Pavillon von 4 Geschossen seinen Abschluss.

Ohne gerade ein Meisterstück der Bankunst zu sein, verdient das Werk Johann Leonhard Dienzenhofers schon uun desswillen höchste Beachtung, weil die Renaissanceordnung bei ihm charakteristisch durchgeführt erscheint: das erste $\mathrm{Ge}$ schoss dorisch, das zweite jonisch, das dritte korinthisch. ${ }^{1}$ )

Für ein zweites Standbild schlug ich vor: den

Markgrafen Friedrich

von Brandenburg-Bayreuth

$1735-1763$.

Friedrichs Regrierungszeit bezeichnet den Höhepunkt in der Entwicklung der Hauptstadt des obergebürgis chen F ürstentums.

Wie sich Bayreuth heute uns zeigt, im Schmucke seiner schönen Strassen und Plätze, seiner teilweise noch vorzüglich erhalteneu Prachtgebäude, seiner Gärten und Anlagen, ist es in wesentlichen eine Schöpfung des Markgrafen Friedrich.

Als seine bedeutendsten Bauwerke sollen

1. das Neue Schloss in Bayreuth,

2. das dortige, noch heute in seltener Frische erhaltene Opernhaus, ein gewaltiges Gebäude, das zur Zeit seines Entstehens das grösste Teater in ganz Deutschland gewesen, und

1) Wild, Karl: Lothar Franz von Schönborn, Bischof von Bamberg etc. etc. Heidelberg 1304 . 
3. die Eremitage bei deren Anblick des Margrafen Schwager, Friedrich der Grosse, zugestehen musste, dass er, der König, dies "nachzumachen nicht im Stande sei", hervorgehoben werden.

Nicht zu vergessen ist aber vor allem, dass dieser fränkische Reichsfürst - angeregt allerdings durch seine geistvolle $\mathrm{Ge}_{\theta}$ mahlin, die Lieblingsschwester Friedrich des Grossen - die Bibliothek in Bayreuth, die Ritterakademie in Erlangen, die Friedrichs-Akademie in Bayreuth und mit deren Verlegung nach Erlangen die Un i versität daselbst gegrïndet und ausserdem eine Zeichen- und Maler-Akademie ins Leben gerufen hat. Endlich verdanken ihm auch die Bayreuther Sammlungen ihren bedeutendsten Zuwachs, da in jedem fürstlichen Schlosse eine Gemäldegalerie eingerichtet worden ist. ${ }^{1}$ )

Nun sah ich mich gezwungen, mit einer gewissen Zaghaftigkeit die Frage aufzuwerfen, ob denn neben diesen beiden kunstsinnigen und baulustigen Fürsten statt eines in der Geschichte wenig bekannten Angehörigen der Reichsritterschaft nicht weit besser ein Vertreter der bildenden Künste des 18. Jahrhunderts, ein berühmter Architekt und Baumeister, der mit der Geschichte aller hervorragenderen neuen Kirchen und Profanbauten im Frankenlande auf das innigste vcrknüpft erscheint, auf dem im Stil des genannten Jahrhunderts errichteten Neubau des Bamberger Archivs einen ehrenvollen Platz finden möchte.

Ein glänzender Name ist es, der mir entyegengetreten und der hier allein in Betracht kommen konnte: Balthas ar Neumann, eines löblichen Fränkischen Kreises Artillerie-Oberst, Bambergischer (und Würzburgischer) Oberingenieur und Baudirektor, der, 1687 geboren, den mächtigsten und wobltätigsten Einfluss auf dem Gebiete der bildenden Künste ausgeübt, zu dessen Zeit sich die Fränkische Kunst zur reinsten, üppigsten Blïte entfaltet hat.

Neben Würzburg, woselbst er einen der schönsten Fürstensitze Deutschlands geschaffen, war es hauptsächlich das Bamberger Land, in welchem Neumann hervorragend tätig gewesen.

1) Siebe Hofmann, die Kunst am Hofo der Markgrafen von Brandenburg, Fränkische Linie, 1901. 
Verpflichtet war er zunächst zu Festungsbauten. Kunsthistorisch wichtiger als diese sind die grossen Aufträge, die er in Bamberg selbst zur Ausführung brachte:

Den Weihbischofshof und das damit verbundene Priesterseminar, das Katharinenspital und das Domkapitelhaus, welches an die Südseite des Domes angebaut ist und von sämtlichen Werken Neumanus die reichste Aussenarchitektur aufweist.

Seiner Schöpfungen sind es staunenswert viele; was hat er nur an Kirchen im Fürstbistum Bamberg alloin entwoder neu gebaut, oder doch umgestaltet:

„Die Hofkirche zu Bamberg, die allbekannte Basilika Vierzehnheiligen, die Wallfahrtskirchen in Gössweinstein und Mariaweiher, die Spitalkirche in Kupferberg, die Pfarrkirchen zu Pretzfeld, Zapfendorf, Oberbrunn, Arnstein, Gunzendorf, Pinzberg, Güssbach, Bechhofen, Unterleiterbach, Giech etc. etc.

Am besten lässt sich vielleicht sein überreiches künstlerisches Schaffen mit dem einfachen Hinweis kennzeichnen, dass er gewissermassen der "Familienarehitekt" jenes schon oben erwähnten, Fränkischen Grafengeschlechtes gewesen, das gerade zur Zeit Neumanns eine Reihe von Fürstensitzen inne hatte und jene glanzvolle Periode in der Deutschen Kunstgeschichte schuf, die man nicht zu Unrecht "das Zeitalter der Schönborn" nennen könnte, dessen erlauchte Glieder ferner überall, wo sie ein Amt inne hatten, oder eine Würde bekleideten, auch Denkmäler ihrer fast sprichwörtlich gewordenen Baulust hinterliessen.

Ebenda kann man aber auch sicher sein, unserem Neumann und seinen Worken zu begegnen.

Bamberg ist vom Ende des 17. Jahrhunderts bis in das dritte Jahrzehnt des 18. Jahrhunderts a n leitender Stelle in der Baukunst geblieben; Bamberger Baumeister und Gesellen sind es, die man in jener Zeit fast überall bei den massgebenden Bauten des Frankenlandes findet. ${ }^{1}$ )

Endlich hatte ich noch der Aufgabe zu genügen, mich gutachtlich darüber zu äussern, welche Figur geeignet sein möchte, an vierter Stelle die im Plane für die Mittelpartie des Neubaues vorgesehene Attika zu schmücken.

1) Siehe: Keller J., Balthasar Neumann, fürstl. Bambergischer etc. Oberarohitekt und Baudirektor, Würzburg 1896. 
Hier drängte sich mir unwillkürlich der Gedanke auf, es können neben einem von Mit- und Nachwelt anerkannten Heros der Kunst nur ein hervorragender Mann der Wissenschaft in Frage kommen. Ist nun dieser zugleich auch Repräsentant der vier mächtigen, im Kreisarchive durch obenso zahlreiche als wertvolle Archivalien vertretenen Abteien Ebrach, Langheim, Banz und Michaelsburg, so dïrfte die Kritik nicht allzu scharf hier einsetzen und weniger streng ihres Amtes walten -

\section{Eugen Montag,}

der letzte grosse Abt von Ebrach, wird ihr vielleicht genügend Stand halten können.

Geboren 1741 als Sohn eines Rechtskonsulenten der altberühmten mächtigen Abtei und Kulturstätte Ebrach, mit deren Schicksalen sein Lebensgang von der Wiege bis zum Grabe auf das engste verknüpft gewesen ist, hatte Montag in immer trüber und unruhiger sich gestaltender Zeit eine tatkräftige, weise und ruhmvolle Regierung bis zur Auflösung seines Klosters geführt.

Den Schwerpunkt seines Wirkens aber haben wir a uf dem wissenschaftlichen Gebiote zu suchen und zwar ist es, was gerade als bedeutsames Moment in der Archiv-Standbilderfrage gelten mag, das Gebiet der Geschichte, auf welchem Montag mit ebensoviel Scharfsinn, als umfassender gründlicher Gelehrsamkeit gearbeitet hat, so dass er ohne Bedenken den grössten, zeitgenössischen Forschern als e ben bürtig angereiht werden darf. Es lebte in ihm unverkennbar ein starker dahin gehender Zug, für althergebracbte Rechte und Freiheiten mit dem ganzen Gewichte seines Wissens, mit streng historischem Aufbau der Argumente auf durchaus solider, quellenmässiger Grundlage einzutreten.

In diesem letzten Ebracher Abte und seinem grossen Zeitgenossen, Fürstbischof Franz Ludwig v. Erthal, „hat die geistliche Herrschaft in Ostfranken kurz vor ihrem Aufhören noch einmal die würdigste Vertretung gefunden".

Vorstehende, vielleicht; zu ausführlich wiedergegebenen Anträge wurden, nachdem sie eine wohlwollende Beurteilung seitens meiner vorgesetzten Stelle erfahren hatten, mit Ent- 
234 Joseph Sebert: Das Kgl. Bayer. Kreisarchiv in Bamberg etc.

schliessung der K. Obersten Baubehörde im Staatsministerium des Innern rom 6. November 190 ? genehmigt; zugleich erging aber noch der Auftrag, allenfalls vorhandene Bildnisse der in Vorschlag gebrachten historischen Persönlichkeiten behufs Anfertigung der Modelle zur Verfügung zu stellen.

Solche ausfindig zu machen, war mit nicht geringen Schwierigkeiten verbunden, doch gelang es Dank dem Entgegenkommen des Herrn Hofoberbaurats Heinrich Handl, des Historischen Vereins Würzburg und des Pfarrers Dr. J. Keller in Mainberg dem Wunsche der höchsten technischen Stelle vollauf gerecht zu werden.

Zum Schlusse muss hier auch der Tatsache noch Erwähnung geschehen, dass unser eben beschriebenes neues Archivgebäude, das zu den schönsten und vornehmsten Monumentalbauten Bambergs zählt und dem ohnehin höchst anmutigen Bild des Stadterweiterungsgebietes einen ganz eigenartigen neuen Reiz verleiht, nach den Plänen des Kgl. Oberbaurates Eduard Reuter von den Architekten J. Beckmann und F. Fuchsenberger ausgeführt worden ist. 